\title{
Producción alfarera en Piura (Perú): estilos técnicos y diacronía
}

La production de poterie à Piura (Pérou) : techniques et diachronie

Pottery production in Piura (Peru): technical styles and diachrony

\section{Gabriel Ramón Joffré}

\section{OpenEdition}

Journals

Edición electrónica

URL: http://journals.openedition.org/bifea/2985

DOI: $10.4000 /$ bifea.2985

ISSN: 2076-5827

Editor

Institut Français d'Études Andines

Edición impresa

Fecha de publicación: 1 diciembre 2008

Paginación: 477-509

ISSN: 0303-7495

\section{Referencia electrónica}

Gabriel Ramón Joffré, «Producción alfarera en Piura (Perú): estilos técnicos y diacronía », Bulletin de I'Institut français d'études andines [En línea], 37 (3) | 2008, Publicado el 01 junio 2009, consultado el 27 noviembre 2020. URL : http://journals.openedition.org/bifea/2985 ; DOl : https://doi.org/10.4000/ bifea. 2985

\section{(c) $(1)$}

Les contenus du Bulletin de l'Institut français d'études andines sont mis à disposition selon les termes de la licence Creative Commons Attribution - Pas d'Utilisation Commerciale - Pas de Modification 4.0 International. 


\title{
Producción alfarera en Piura (Perú): estilos técnicos y diacronía
}

\author{
Gabriel Ramón Joffré*
}

\begin{abstract}
Resumen
Interesados en identificar marcadores de identidad colectiva (etnicidad), los arqueólogos han renovado sus estudios sobre talleres alfareros para identificar los modos de producción de objetos (estilos técnicos). Estos tres conceptos (identidad colectiva, talleres alfareros, estilos técnicos) han sido forjados por la etnografía. Sin embargo, el testimonio etnográfico es también histórico: cambia en el tiempo y el espacio. Por lo tanto discutiré la variabilidad sincrónica en las formas de producción cerámica de una amplia región al norte del Perú y sus usos en la interpretación del pasado (precolonial) a través de objetos.
\end{abstract}

Palabras clave: producción alfarera, arqueología, etnografía, cultura material, Olleros

\section{La production de poterie à Piura (Pérou) : techniques et diachronie}

\section{Résumé}

Afin d'identifier des marqueurs de l'identité collective (ethnicité) les archéologues ont renouvelé leurs études sur les ateliers de poterie afin d'identifier les manières de produire des objets (styles techniques). Ces trois concepts (identité collective, ateliers de poterie, styles techniques) ont été mis en place par I'ethnographie. Toutefois les témoignages ethnographiques sont aussi historiques : ils se modifient en fonction du temps et l'espace. Aussi cet article examinera-t-il la variabilité synchronique des façons de produire la céramique d'une vaste région du nord du Pérou et l'utilisation que l'on peut en tirer pour interpréter le passé (précolonial) à partir des objets.

Mots clés : production céramique, archéologie, ethnographie, culture matérielle, Olleros 


\title{
Pottery production in Piura (Peru): technical styles and diachrony
}

\begin{abstract}
Looking for markers of collective identity (ethnicity) archaeologists have renewed their studies on the pottery workshops, in order to identify modes of making objects (technical style). These three concepts (collective identity, pottery workshops, technical style) have been shaped by ethnography. Nevertheless, the ethnographic evidence is also historical: it changes in time and space. In the following, this essay will discuss the synchronic variability of pottery techniques in a vast region of northern Perú and its implications for the interpretation of the (pre-colonial) past through objects.
\end{abstract}

Key words: pottery production, archaeology, ethnography, material culture, Olleros

\section{INTRODUCCIÓN}

Antes de iniciada la arqueología andina, ya se recurría a las analogías etnográficas para explicar la cultura material precolonial. Tal fue el caso de Samuel Scott en Piura. Al presentar los resultados de sus excavaciones en el valle del Chira, este anticuario usó un procedimiento que se haría rutina, tras declarar la decadencia de la población indígena anotaba que «un estudio de las prácticas de los nativos actuales a la luz del material recolectado muestra una notable supervivencia de las antiguas industrias y métodos» (1895: 21; original no subrayado). Paso seguido, describía la técnica del más renombrado pueblo de alfareros de la región. Desde entonces, Simbilá ha sido la referencia para explicar la producción cerámica arqueológica de la costa norte, pese a la diversidad del presente etnográfico de la región, y sin asumir la complejidad del enfoque histórico directo1.

A continuación se analizarán las técnicas alfareras actuales del departamento de Piura. Se describen enfatizando la evidencia material de la manufactura (conjunto de herramientas), definiendo zonas de producción, para esbozar patrones regionales². Se busca mostrar la utilidad de considerar los modos colectivos de elaborar objetos como evidencia cultural (estilo técnico). Finalmente, se discute la relación etnografía/arqueología piurana y en especial su nexo: la diacronía de la cultura material. En el tema de la producción alfarera, considero que la etnografía ha modelado la arqueología, y asumirlo permitirá establecer medios eficaces de usar analogías para explicar material precolonial3.

Centrarse en el conjunto de herramientas (y sus improntas) es una manera precisa de vincular evidencia etnográfica y arqueológica. El taller alfarero es solo un modelo etnográfico proyectado (en el mejor de los casos como interrogante) al registro fósil. Ningún arqueólogo ha visto a un alfarero prehispánico en acción: simple y llanamente lo imagina académicamente mediante ejemplos del vademécum etnográfico (Shepard, 1965: 4994; Rye, 1981; Rice, 1987: 133-167). Para inferir la presencia de un taller alfarero, los

1 Bingham (1915: 257, 260-261, fig.1) radicalizó el «método Scott»: explicó la técnica de las vasijas de Machu Picchu usando a las olleras del Coropuna (Arequipa). Sobre el enfoque histórico directo, ver Lyman \& O’Brien (2001).

2 La etnografía alfarera norperuana comienza con Castro-Pozo (1924: 297-300). La odisea etnográfica de Sabogal resultó en una serie de reportes $(1978 ; 1981 ; 1982)$. Basada en uno (1982), Monzón (1991) publicó un útil esquema. Aquí enfatizaré en las técnicas serranas, descritas usando nuestras notas de campo [ver Agradecimientos], contrastadas con la escasa literatura; y viceversa para la costa, largamente estudiada. La bibliografía de Piura puede consultarse en Revesz et al. (1996: 636-643).

3 En la discusión sobre analogía etnográfica, empleo a Orme (1981), Salmon (1982) y Wylie (2002). 
arqueólogos han usado diversos criterios. Por ejemplo, Rice (1987: cuadro 6.3, 177-180) indica dos tipos de rasgos: por ubicación (proximidad a fuentes de arcilla de alta calidad, a comunidades alfareras modernas) y por presencia de elementos diagnósticos (hornos, de áreas calcinadas, instrumentos de alfareros, desechos de quema, reserva de materias primas, cantidad de vasijas sin quemar, entre otros). Ninguno, aislado, es suficiente y tienen diversos status heurísticos. Conviene detenerse brevemente en un caso, el de la «proximidad a las fuentes de arcilla de alta calidad» a la luz de nuestro corpus etnográfico. La distancia entre talleres y yacimientos varía mucho: solo en Piura y Lambayeque, va de siete minutos a cuatro horas a pie, de ida. La calidad depende de la fuente, el procesamiento y el producto esperado. Más aún, no todo yacimiento geológico es cultural. Los primeros abundan en los Andes, pero lo que debe probarse es su vínculo con el producto de la actividad humana, por ejemplo, las ollas4.

Sin negar la utilidad informativa de otros aspectos de la producción enfatizaré aquí en el conjunto de herramientas, por su visibilidad arqueológica y haber sido descrito por etnógrafos 5 . Cuando los arqueólogos recurren a ejemplos modernos de producción alfarera, un criterio selectivo es la técnica, vinculada a las herramientas. La presencia del conjunto de herramientas permite inferir que estamos ante un taller que, por lo general, es un tipo de recinto arquitectónicamente vago. Además, las técnicas alfareras ofrecen rasgos clasificables para obtener una definición completa de estilo, y pueden inferirse a través de las herramientas y/o sus improntas en las vasijas6.

\section{ALFAREROS DEL LITORAL (SIMBILÁ, OLMOS, MÓRROPE)}

Situado entre dos desiertos (Tumbes y Sechura) el litoral piurano es el más amplio del país, llegando a exceder los $120 \mathrm{~km}$ en línea recta. Esta planicie aloja tres tipos de asentamientos bajo los 150 metros: ocupaciones costeras (Paita, Sechura), intermedias en la mejor ubicación agrícola (Sullana, Piura) y puertos serranos (Chulucanas, Morropón). Los pueblos con alfareros discutidos en esta sección se ubican en este ámbito geográfico7 (fig. 1).

\section{1. Simbilá (36 $\left.\mathrm{m}, 5^{\circ} 14^{\prime} 55 \mathrm{~S}, 8^{\circ} 39^{\prime} 11 \mathrm{O}, 3150 \mathrm{~h}\right) 8$}

Pertenece al distrito de Catacaos, antigua reducción, y tiene dos zonas: una de edificaciones bajas de concreto, y Simbilá viejo, con casas de caña y barro, donde vive la mayoría de olleros. La alfarería es intensiva, en parte por su relación con la preparación semanal, almacenamiento y consumo diario de chicha en las zonas rurales (Camino, 1982: 26-29; 1987).

4 El Análisis por Activación de Neutrones tiene sentido donde hay una base de datos sobre potenciales fuentes de arcilla singularizadas con rasgos diagnósticos. Requiere estudios específicos, que confirmen que la correspondencia empírica entre fuentes y productos es físicamente identificable. Pruebas de este tipo — con resultados negativosse hicieron en Yucatán, México (Arnold et al., 2000) y otros lugares. Los raros casos de AAN de cerámica en los Andes obvian este requisito.

5 Por razones de espacio el procesamiento de materias primas y la quema serán solo brevemente tratados, pero el lector es remitido — de existir - a la bibliografía pertinente.

6 Concluida nuestra clasificación de técnicas alfareras y herramientas en cerca de treinta comunidades con alfareros de los Andes Septentrionales peruanos — Ancash, La Libertad, Lambayeque y Piura (mayo de 2007) — hemos confirmado dos hipótesis de trabajo para esta zona: i) en cada pueblo con alfareros todos usan una misma técnica; ii) a cada técnica corresponde un conjunto de herramientas. Por supuesto que hay algunas excepciones, que no podemos detallar aquí. Para el caso de Simbilá, ver más adelante en la sección 3.

7 Actualmente Olmos y Mórrope se ubican en el departamento de Lambayeque.

8 En adelante, $\mathrm{m}$ : metros $\mathrm{y}$ h: habitantes. 


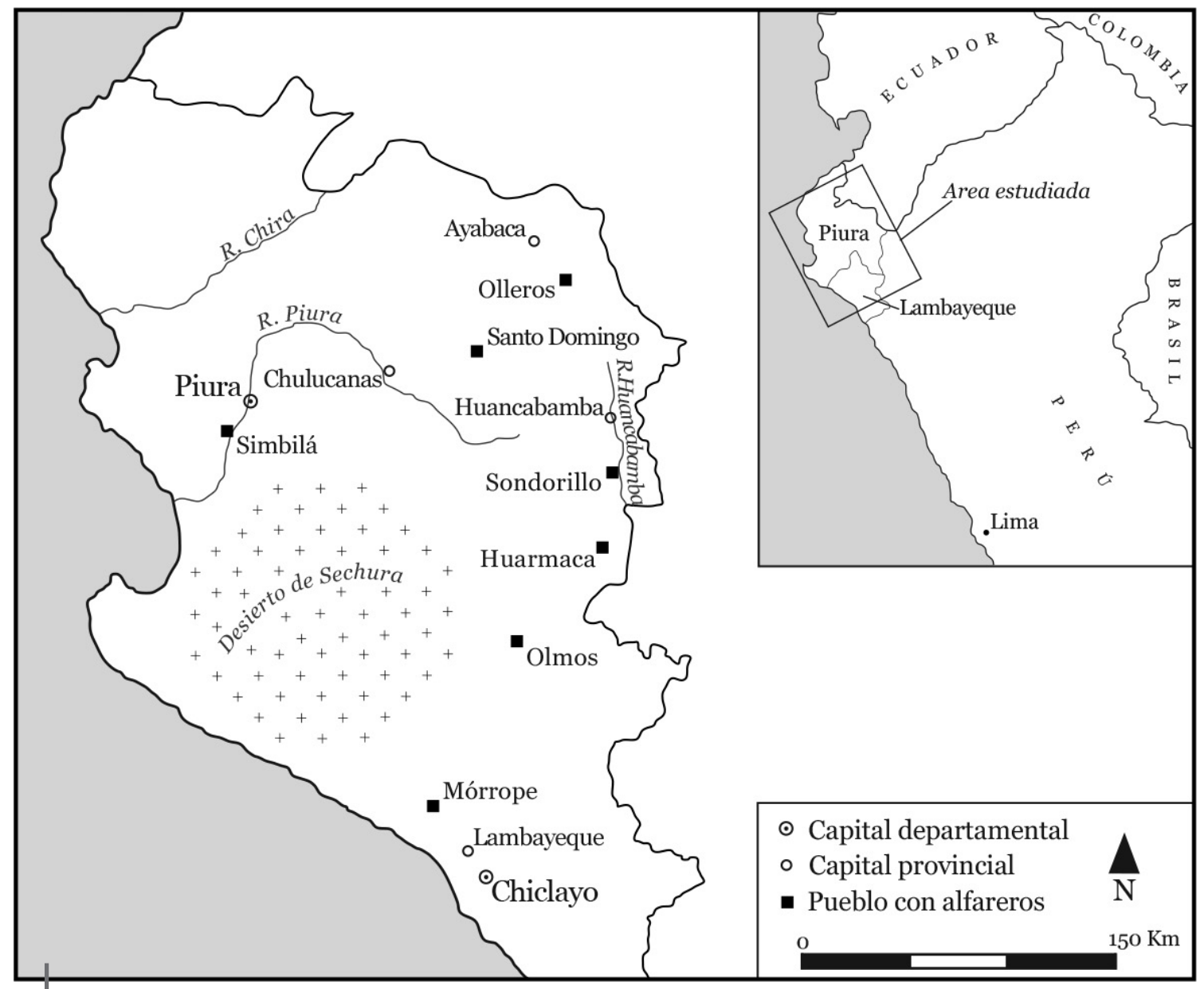

Figura 1 - Pueblos con alfareros mencionados en el texto

Olleros, Santo Domingo, Sondorillo, Huarmaca, Simbilá, Olmos (Lambayeque), Mórrope (Lambayeque)

Describir la técnica simbileña implica un detalle adicional: tiempo en etnografía (Rowe, 1955). Dos décadas antes de Scott, Raimondi (1901 [1868]: 154) había visitado Simbilá, aludiendo escuetamente a la «fabricación de ollas y cántaros». Según Scott, Simbilá era excepcional: una comunidad endógama, aislada, con traje propio, dedicada al trenzado de paja (para sombreros) y la alfarería9. Esta última actividad era masculina, y sobre la técnica indicaba:

9 Evidencia de la peculiaridad simbileña en la lista de Martínez Compañón (1985 [1790]), que incluye la «Lengua de Catacaos» distinta a las de Colán y Sechura (Cerrón-Palomino, 1995: 48). 
«esta arcilla se forma a mano, con herramientas de madera, sobre piedras redondeadas, en forma de ollas ordinarias para cocinar y otras vasijas de uso común. El cuello o boca se hace en una pieza separada y unida al cuerpo en una operación aparte» (Scott, 1895: 21; original no subrayado).

Hoy, pese a la presencia de plástico y metal (reemplazando yute, mate, madera) y la introducción de nuevas formas de vasijas, los rasgos del «paleteado» son similares a los reportados anteriormente10. La actividad sigue siendo masculina, con raras excepciones. En 1876 se contaron 62 alfareros (13 mujeres), 60 en 1980 y 70, en la actualidad (Censo, 1878, VII: 138; Camino, 1982: 13; López com. pers., 2004). Los alfareros trabajan en la estación seca (abril/mayo-diciembre). La arcilla y la arena se extraen de un área deshabitada del poblado de La Legua (23 m, 5¹3'18 S, 8040’10 O), a media hora 11. En este, y todos los casos a seguir, la arcilla y el material adicional (por ejemplo, «arena», «mezcla» $\mathrm{u}$ otras arcillas) son procesados y la combinación se almacena bajo sombra12.

\section{1. 1. Herramientas}

El conjunto básico incluye dos paletas de algarrobo, hechas por los alfareros o heredadas. Hay dos variantes: una gruesa [desgasadora] para formar y adelgazar las paredes y otra para nivelar [emparejadora]. La piedra es yunque. Un alfarero (E. Martínez), de acuerdo a la descripción presentada tenía dos tipos de paletas, de tamaños distintos, relacionados con las vasijas a producir (fig. 2)13. José Ipanaqué nos mostró que además de estos tipos puede usarse una intermedia, para borrar las marcas de la desgasadora. No es cuestión de tamaño o forma, ya que son similares, sino de espesor: tras años de uso, la desgasadora se hará emparejadora, o mantendrá su función pero con vasijas chicas (fig. 3). Se usan además
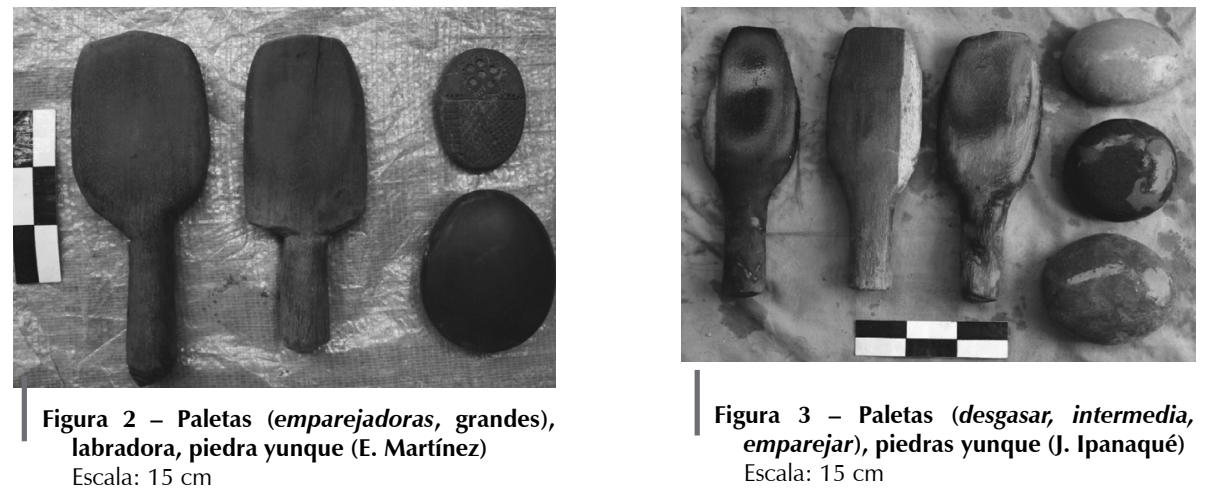

10 Tuve que comparar Christensen (1955 [1950]), Respaldiza (1953 [1945]), Quiroz (1986 [1949-1950]), Spanhi (1966; 1979), Litto (1976: 13-15), Tillman (1978), Camino (1982), Thays (en Sabogal, 1982: II: 115159) y CEICAD (1986). La investigación en Simbilá permitió aclarar puntos oscuros en descripciones previas. Conversamos con dos alfareras y una docena de alfareros de dos talleres. Uno, dirigido por Sebastián López Raymundo (51) hijo del fundador, Medardo López Yamunaqué (†). Trabajan allí 10 alfareros [un hijo de S.L. (Heladio), un hermano (Pascual), primos y sobrinos (José Ipanaqué)]. Cristina, hija de S.L., ayuda en algunas tareas. Esteban Martínez López (36) — sobrino de Sebastián e hijo de Mercedes M. L.— posee el segundo taller y tiene dos asistentes. La segunda alfarera, Anita Raymundo Paz (prima de S.L., hija de Enrique R.) trabaja en su casa, con las herramientas paternas.

11 Todos los trayectos serán a pie, de ida, salvo que se indique lo contrario.

12 Desde este punto, las denominaciones vernáculas de artefactos y materiales irán en cursivas.

13 Esta descripción [2 funciones/2 tamaños +4 variedades] coincide con Sosa (1984: 27) para Chulucanas. Véase CEICAD (1986: 16) y Sabogal (1982, II: 140). 
sellos decorativos [labradoras o shimbas] (fig. 2), guijarros de pulir, un cuchillo, una vasija para el agua y retazos de tela. Un trozo de plástico o textil sirve de superficie de trabajo y para cubrir las vasijas.

\section{1. 2. Elaboración}

El «Comenzado» no emplea herramientas. El ollero se sienta con un trozo de arcilla sobre las piernas y lo golpea con el puño formando un cono (figs. 4-5). Para vasijas mayores (tinajones) agrega rollos para obtener un cono grande, con un orificio al tope $(\mathrm{ca} 10 \mathrm{~cm})$. Siendo un trabajo en serie, la elaboración de una pieza puede continuar horas después, o al día siguiente, según cantidad y tamaño. En el segundo paso [«alisado»], la postura del alfarero varía, de acuerdo a las dimensiones de la vasija: con las menores, permanece sentado, ayudando a su rotación con los pies'14.

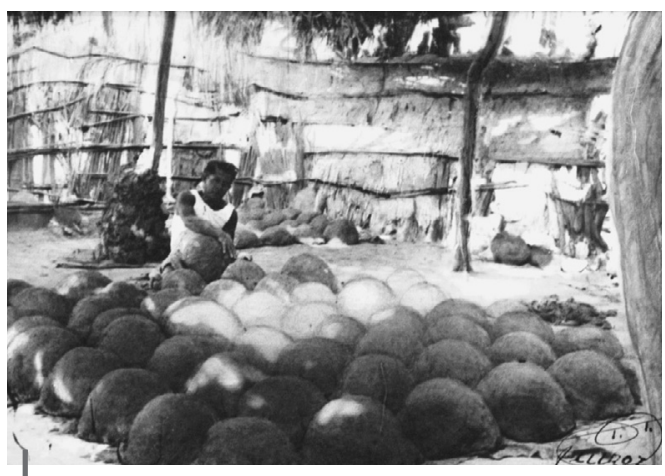

Figura 4 - «Primer día de trabajo»: haciendo el cono (1949-1950)

Colección Quiroz 13, CIPCA

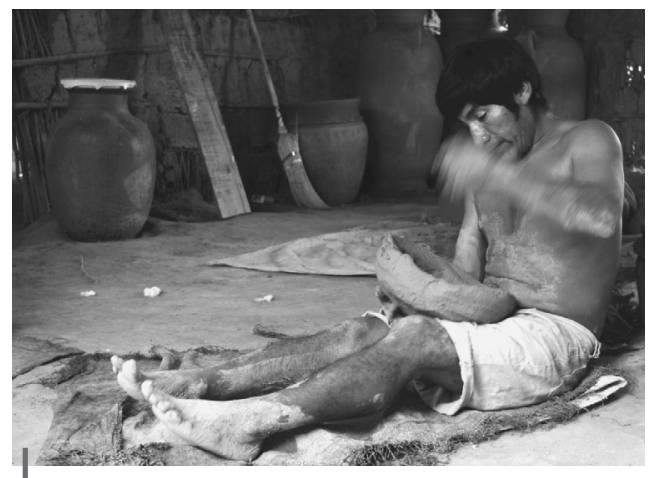

Figura 5 - Comenzada: haciendo el cono (E. Martínez)

Con las grandes mayormente se trabaja de pie moviéndose alrededor15 (fig. 7). Golpea por fuera con la desgasadora, y al interior va la piedra. Como los tinajones son muy grandes para ser volteados antes del tercer día, durante el alisado la perforación superior permite modificar el interior de la vasija. Al concluir, cierra el hueco y crea otro a media altura de la vasija. Paletea la sección superior del tinajón para obtener el mismo patrón, y cierra el orificio. Ahora la vasija muestra una superficie uniforme. Luego de secar una segunda noche, comienza el asentado, en que va reemplazando la desgasadora por las más delgadas [intermedia, emparejadora] y voltea la vasija. Esta va en una depresión del piso y el ollero la paletea, hasta que las paredes se reducen a la mitad del grosor previo (fig. 7). En el cuarto paso [echada de boca], agrega un grueso rollo al borde y paletea con la emparejadora. Luego agrega adornos, como el cordón (rollo agregado a la superficie) y la estampa con una mazorca.

El resultado es una serie de tinajones $(24 \mathrm{~kg} \mathrm{c} / \mathrm{u}$ ). Luego de secar (15 días de sombra, 2 de sol) los pintan con ocre y están listos para el fuego. La quema se realiza en grandes hoyos semisubterráneos de aproximadamente cinco metros de diametro y uno y medio

14 Una secuencia para vasijas chicas con la técnica simbileña en Yamunaqué (1979). También, Spanhi (1966: 23) para Sojo y Chira (1979: 28); Sabogal (1982, I: 220; II: 188-194) en Sullana y en Chulucanas (I: 237).

15 Véase Sabogal (1982, II: 169) en Chulucanas y en La Legua (I: 194-198). Algunos artesanos permanecen sentados con las vasijas grandes (fig. 6), veáse Litto (1976: 14) y Sabogal (1982, I: 219) para Sullana. 
de profundidad (Camino, 1982: 55-60). Las vasijas son mayormente para chicha y comida (ollas, cántaros, tinajas, tinajones) y entre las de uso urbano destacan los floreros, tinajones decorativos y bases de lámparas. Como los alfareros están abocados a la producción, la distribución la asumen las mujeres y los vendedores. Las vasijas se venden en el mercado de Catacaos o vía intermediarios, van por la costa piurana y alrededores; por ejemplo, cada semana un camión de Chimbote (más de $700 \mathrm{~km}$ al sur) llega a Piura con harina de pescado y de regreso, lleva cerca de treinta tinajones del taller de Sebastián16.

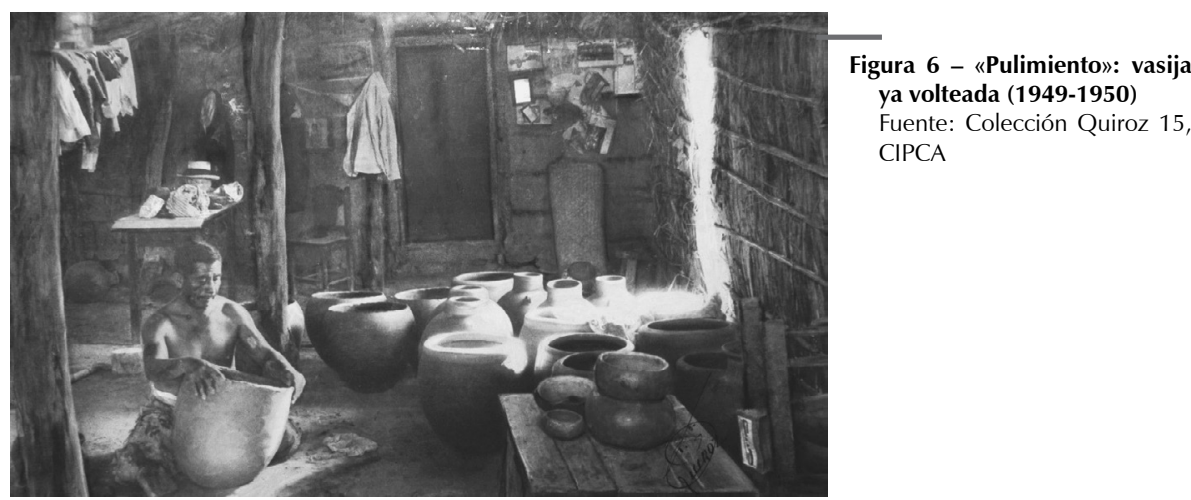

Figura 7 - S. López (al frente) alisando un tinajón. J. Ipanaqué, asentando

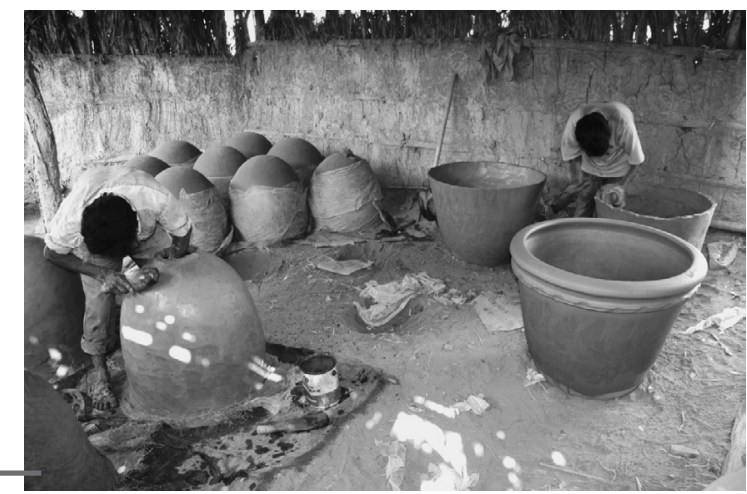

\section{2. Pares por el desierto}

El paleteado no es solo simbileño. Esta técnica llegó a Chulucanas (Morropón) en la década de 1920: tras un temblor, algunas familias de alfareros migraron y aprovecharon la arcilla local (Camino, 1982: 105-106)17. Este caso es parte de una serie. La distribución de la técnica ha resultado de un patrón dinámico, vinculado a los golondrinos. Al menos desde fines del XIX, este tipo de alfarero itinerante ha estado circulando por el desierto de

16 Sobre tipos de vasijas, véase Camino (1982: 62, 69-72); Sabogal (1982, I: 47; II, 155-159) y CEICAD (1986: 11-12). Para la distribución, Sabogal (1978; 1982: I), Camino (1982: 104) y CEICAD (1986).

17 Chulucanas es conocido por el grupo Saño-Camayoc (dirigido por Gerásimo Sosa, cuyo padre emigró de Simbilá). No lo discutiré: ellos han desarrollado sus propias técnicas no relevantes para nuestros propósitos, su técnica tradicional es la de Simbilá y han sido repetidamente registrados (Sosa, 1984). 
Sechura y alrededores. Era de Simbilá y algunos meses al año trabajaba en otras áreas con sus instrumentos y arcilla local o propia, y cambiaba sus vasijas donde las producía. Los golondrinos generalmente regresaban a casa luego de la estación seca, como sucedía en Cruz Pampa, Morropón, Querecotillo (Sullana), Sullana y Tambo Grande (Sabogal, 1982, I: 54-56; Camino, 1982: 95)18. Ocasionalmente se quedaban en los caseríos visitados, como pasó en La Bocana (Morropón), La Encantada (Chulucanas), La Huaca (Paita), La Legua (Catacaos) y La Unión (Chulucanas) (Sabogal, 1982, I: 58-60, 63-67, 62-63, 56-58; 1987: 26-30; Camino, 1982: 95-96). El caso documentado más antiguo de un golondrino se sitúa en Olmos (Lambayeque) ${ }^{19}$.

\section{2. 1. Santo Domingo de Olmos (194 m, $5083 \mathrm{~h})$}

Está al extremo sur del Sechura, cerca al río Olmos. Lejos del mar, ha servido de posta entre Piura y Lambayeque. Tras varios desplazamientos fue reducido (1573), juntando gente de dos áreas lingüísticas (sechura, mochica) promoviendo una lengua propia que - luego de años como arrieros del desierto- devino lengua franca (Brüning, 1922-1923: 45-47, 72; Torero, 1986: 543-545).

En 1889, Brüning (1898) entrevistó a un golondrino sedentarizado. Nativo de Catacaos, había llegado a Olmos recientemente. Viajaba con sus herramientas y ubicó yacimientos de arcilla. Producía ollas de diversos tamaños, vasijas chicas y tejas. Trabajaba sentado en el piso con trozos de arcilla (conos aplastados) para cada vasija. Empleaba un canto rodado, que iba bajo el cono y una paleta de madera $\left(28 \mathrm{~cm} \mathrm{I}, 6 \mathrm{~cm}\right.$ a) ${ }^{20}$ con la que golpeaba por fuera (fig. 8). Rotaba la pieza con el pie mientras paleteaba hasta obtener la forma básica. Añadía un gran rollo para formar el borde y concluía pasándole un pedazo de tela. Normalmente hacía 48 ollas medianas al día.

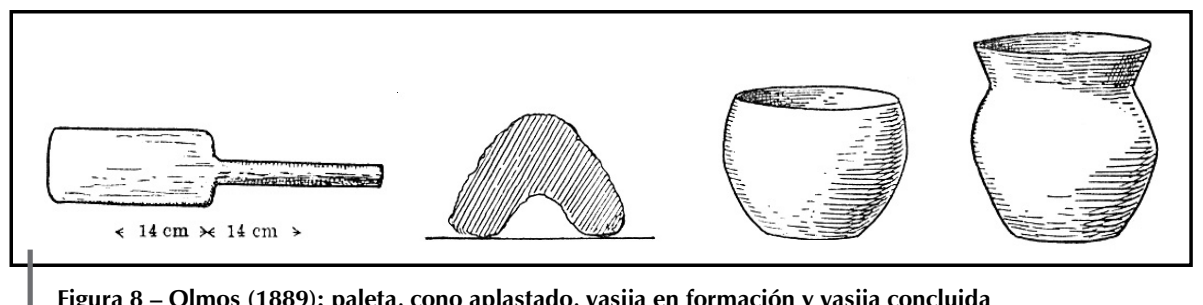

Figura 8 - Olmos (1889): paleta, cono aplastado, vasija en formación y vasija concluida Fuente: Brüning (1898)

Este alfarero no estuvo aislado. Al menos desde fines del siglo XIX, Olmos ha sido un destino constante para los golondrinos. Actualmente, hay pocos alfareros activos, como Simón Martínez Mío (54) oriundo de El Imperial (191 m, 558'23 S, 7943’58 O, 211 h). Su abuelo (Pedro Martínez Yamunaqué) era simbileño y se quedó en Olmos entre 1920 y 193021.

\footnotetext{
18 En adelante, para localizar los poblados y caseríos puede consultar <http://desa.inei.gob.pe/mapas/bid/> .

19 El término golondrino es de Sabogal (1987: 18-19), quien distinguió entre los que viajan sin arcilla (Morropón) o con ella y sus herramientas, como los cajamarquinos (Cusquidén, San Pablo) que iban a Chepén, Paiján, Ascope, Pacasmayo, Guadalupe y otros lugares de la costa norte (Espejo, 1951). Los golondrinos del Callejón de Huaylas (Ancash) visitaban Quihuay (valle del Santa) con su arcilla (Donnan, 1971: 464-465).

20 Las medidas de los artefactos van en centímetros (cm): largo [l], ancho [a], grosor [g], altura [al] y diámetro [Ø].

21 Martínez y Yamunaqué son apellidos frecuentes entre los alfareros simbileños (Camino, 1982: 129-131). Brüning (1922: 53) identificó a los Mío en Ficuar (Olmos). Sabogal (1978: 38-39; 1982, I: 68-80) entrevistó al ollero Mildo Martínez (Olmos), cuyo padre llegó de Simbilá en la década de 1920 y descubrió una fuente de arcilla.
} 
Hace cuatro décadas Simón aprendió de su padre (Nazario M. M.), quien creó el taller. Paletea de junio a diciembre, y se dedica a la agricultura el resto del año. La cantera de arcilla está a una hora en burro (laguna del Carmen, 4 km). Extrae la mezcla [arena] de la ribera del Olmos $(2 \mathrm{~km})$.

- Herramientas. Usa dos tipos de paletas de algarrobo $(27 \mathrm{~cm} \mathrm{I,} \mathrm{9-10} \mathrm{cm} \mathrm{a,} \mathrm{3,5} \mathrm{g):} \mathrm{una} \mathrm{para}$ refinar las paredes [desgasar] y otra para nivelar la superficie [alisar]. Además una piedra yunque, una coronta para decorar, un cuchillo, un palito, un clavo, un pedazo de tela y dos guijarros de pulir (fig. 9).

- Elaboración. El comenzado de una olla consiste en formar el asiento (cono achatado) con las manos. Al siguiente día, se golpea el cono con la paleta más pesada [desgasadora] y la piedra, para adelgazar las paredes (fig. 10). El paleteado continúa con la alisadora. Como el ollero de Brüning y sus colegas de Simbilá y Chulucanas (Sosa, 1984: 30), Simón usa el pie derecho para rotar la vasija. Luego del secado nocturno, el tercer día es el terminado, se agrega arcilla y se golpea con la alisadora hasta lograr el grosor deseado. El cuello se forma con el pedazo de tela. El hueco tipo cráter para quemar fue hecho por su padre. La disposición de los materiales es como en Simbilá: base de leña (zapote), vasijas y una capa de callanas [tiestos grandes] cubiertos con bosta caprina y panca. Simón produce ollas de diversos tamaños, tinajas, cántaros, floreros, cazuelas, librillos, tostadoras y jarras 22. Vende en otros caseríos del distrito (Chucular, Querpón, Corral de Arena), pueblos próximos (Íllimo, Olmos, Motupe) y Chiclayo.

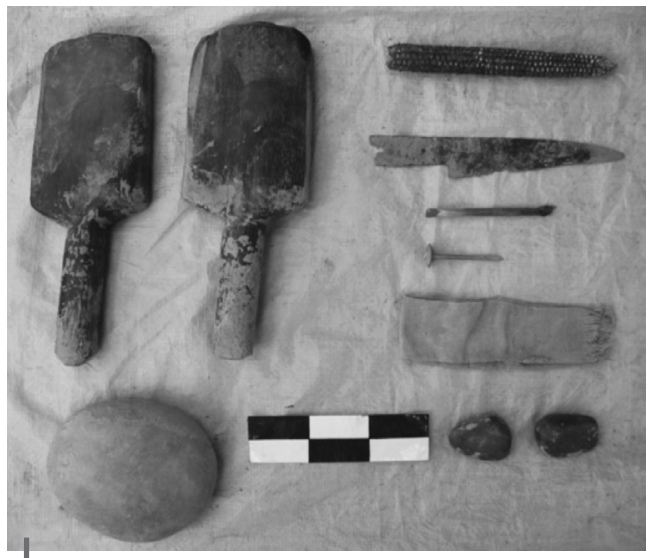

Figura 9 - Paletas (desgasadora, alisadora), piedra yunque e instrumentos complementarios Escala: $15 \mathrm{~cm}$

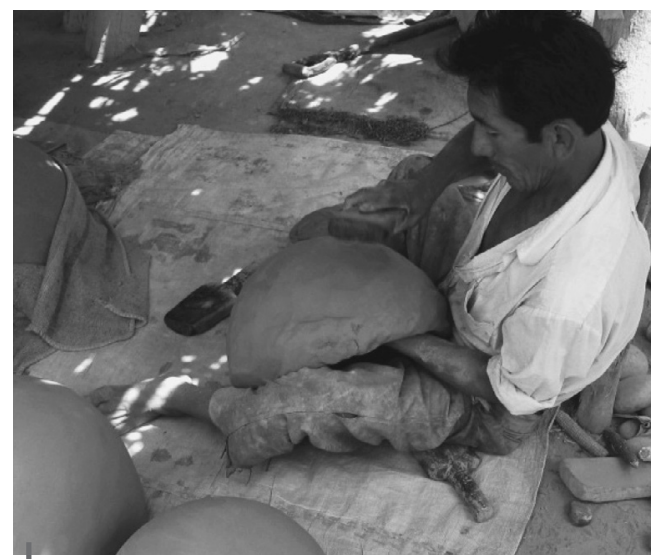

Figura 10 - S. Martínez usando la desgasadora

\section{2. 2. San Pedro de Mórrope (25 m, 3719 h)}

Está al extremo suroeste del Sechura, 70 km en línea recta de Olmos. Mórrope deriva de iguana ['mur] en mochica, y se ubica en esa extinta área lingüística (Brüning, 2004: 36; Torero, 1986: 529). En 1540, se registraron 3 olleros en Jayanca, valle al que pertenecía Mórrope (Espinoza, 1975: 264). En 1876, se censaron 8 en Mórrope (distrito) y 6 en sus alrededores (Ferreñafe, Jayanca, Lambayeque, Mochumí) (Censo, 1878: V, 684, 649, 663, 670, 677).

22 En los años de 1980, los tipos de Olmos (Sabogal, 1982, I: 72, 74-81) eran como los simbileños de Christensen (1955). 
La primera descripción de la técnica de Mórrope menciona diez familias alfareras (Collier, 1959 [1956])23. Los alfareros han cambiado de residencia durante el siglo pasado debido a las inundaciones (1943, 1972 y 1983). Hoy un grupo vive en las afueras del pueblo y la mayoría en los caseríos: por ejemplo, San Antonio, Annape y Ollería. Al menos desde la última inundación, 17 alfareros trabajan en Ollería. El oficio es masculino y se ejerce en la estación seca. Las mujeres tejen en el telar y la comunidad posee minas (yeso, sal) donde los pobladores trabajan por turnos 24 .

Luis Alberto Chapoñan Inoñán (48) aprendió de su abuelo, Exaltación Inoñán, cuyos artefactos heredó. Vive en Ollería (24 m, 6³0’00 S, 8000’01 O, 410 h) dedicado a la alfarería (septiembre-enero) y otras ocupaciones periódicas (mina de cal). Obtiene arcilla de Chochor (4 horas, al oeste) en un terreno de su familia materna. La arena es de Romero (a 10 min).

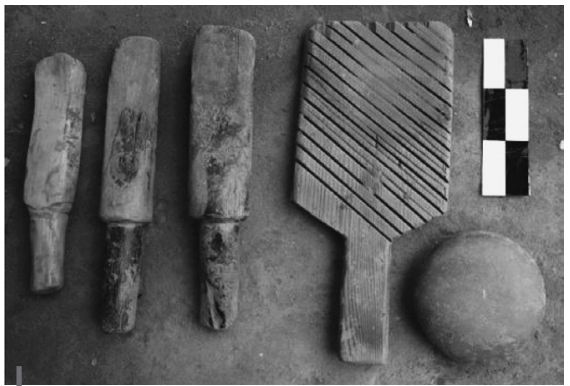

Figura 11 - Mazos (3), palmeta, piedra yunque Escala: $15 \mathrm{~cm}$

- Herramientas. Usa cuatro moldes, de 2, 3, 4 y 8 latas, y uno chico para jarras 25; dos paradores, grandes vasijas semienterradas en el piso del taller, llenas de arena, que sostienen el molde; la champera, semi-enterrada, cerca a la pared, con agua para la arcilla; una palmeta de madera $(32 \mathrm{~cm} \mathrm{I}$, $15 \mathrm{~cm}$ a, $2 \mathrm{~cm} \mathrm{~g}$ ) con un lado inciso con líneas transversales; tres mazos de algarrobo $(23-29 \mathrm{~cm} \mathrm{I}, 5-6 \mathrm{~cm}$ a), un canto rodado recogido de la playa por su abuelo, un cuchillo, un retazo de tela y dos palitos (fig. 11)26.

- Elaboración. El molde va sobre el parador. Tras humedecer y agregar arena sobre el molde, el alfarero pone encima un trozo de arcilla (fig. 12)27. Lo expande y presiona con las manos sobre el molde hasta obtener un cono aplanado. Tras secar de noche, el cono volverá sobre el molde, y será golpeado con la palma y el mazo. Cuando las paredes están suficientemente delgadas, se usan ambos lados de la palmeta, agregando arcilla. De aquí al final del proceso, el alfarero rota alrededor de la vasija al trabajar. El resultado es una forma de paredes delgadas que reproduce al molde. Tras un segundo secado, el futuro recipiente es volteado y puesto sobre el parador solamente — si es grande como una tinaja-, o sobre el parador y el molde —si es pequeño, como una olla-. Se combina palmeta y mazo según la forma esperada, con la piedra como yunque. Para la tinaja, se agrega un rollo de arcilla para hacer la boca, formada pasando la tela. Para los detalles finales (como el asa de las jarras) se usa el cuchillo y el palito.

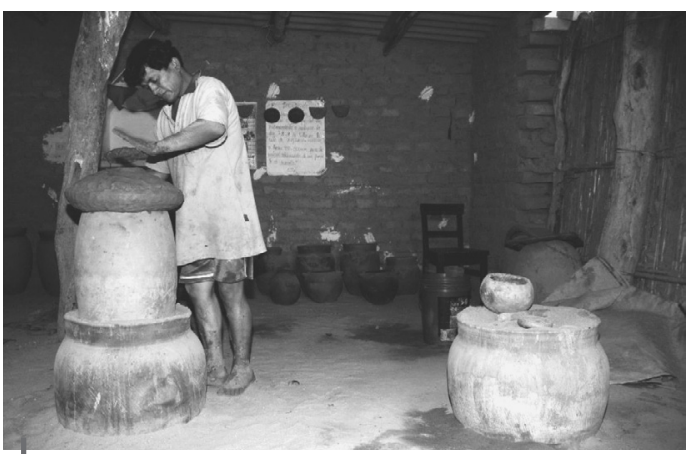

Figura 12 - L. A. Chapoñán, iniciando el proceso, con el barro en el molde y sobre el parador

23 Evidencias de la actividad alfarera en las fotos de Brüning (Schaedel, 1988: 116-117, 130; Raddatz ed., 1990: 88).

24 Vivimos dos semanas en Ollería. La información fue proporcionada por L. A. Chapoñán Inoñán, Eduardo Santisteban Bances (36), Rafael Reyes Baldera (50, San Antonio Annape), José Manuel Santisteban (70), José Isaías Vidaurre Zeña (73, San Sebastián) y Sara Inoñán [cuando la persona no es de Ollería, se indica el lugar].

25 Acertadamente, Collier (1959) denominó convex pot-mould a los moldes ya que son como las vasijas normales, volteadas. Una lata es 18 litros (S. Martínez, Olmos).

26 Puede agregarse el sello de cerámica, que no vimos (ni su impresión en vasijas) pero ha sido registrado en Collier (1959: 367-368); La Industria (21/10/1984); Leertouwer (1987: 71) y Bankes (1988: 568).

27 El proceso en Collier (1959); La Industria (21/10/1984); Bankes (1985; 1988); Leertouwer (1987) y Shimada (1994a). 
Luis Alberto quema en hoyos redondos ( $1 \mathrm{~m}$ al, $3 \mathrm{~m} \varnothing$ ), con base de leña (zapote) y las vasijas, y cubre todo con bosta caprina y callanas 28 . Las formas principales son cántaros, tinajas, mulos (cántaro para chicha) y ollas. Vende localmente y en mercados al norte de Lambayeque (Mórrope, Chiclayo, Mochumí, Pacora, Jayanca, Motupe) e incluso Piura29.

\section{EL MOSAICO SERRANO (HUARMACA, SONDORILLO, SANTO DOMINGO, OLLEROS)}

El prestigio de los alfareros de la costa y una historia de segregación han provocado la invisibilidad etnográfica de sus pares serranos. El censo de 1876 (1878: VII, 59) los ignora. En Piura, la vertiente occidental andina está muy lejos del mar y es la más baja del país. Sus cimas están al este, entre Ayabaca y Huancabamba (laguna Negra y Shimbe, 3960 m y $3942 \mathrm{~m}$ ) y al sur, el paso cordillerano está a solo 2000 m (Abra de Porcuya, Huarmaca). Esto permite imaginar la variedad ambiental en esta serranía, área de transición entre los húmedos Andes ecuatorianos (páramo) y los secos Andes peruanos (puna). El promedio pluvial anual aumenta con la proximidad al Ecuador y la altitud. Según los olleros y las estadísticas, llueve entre diciembre y abril30.

La sierra se divide en tres secciones de norte a sur: Ayabaca (sin los distritos de Frías y Pacaipampa), donde la altitud y la proximidad a la Amazonía crean un ambiente de jungla alta; Morropón (incluyendo Frías y Pacaipampa), irrigado por los principales ríos de la región; y Huancabamba, con variedad climática, pero caracterizada por una región central árida. Estas tres áreas han estado aisladas y se han caracterizado por la presencia de haciendas y comunidades, relacionadas solo entre ellas. Tras visitar Ayabaca y Huancabamba, Raimondi afirmó:

«Estos indígenas no frecuentan los pueblos sino en los días de fiesta; viven casi independientes del gobierno y ven con malos ojos hasta al mismo cura» (1874 [1868]: 375).

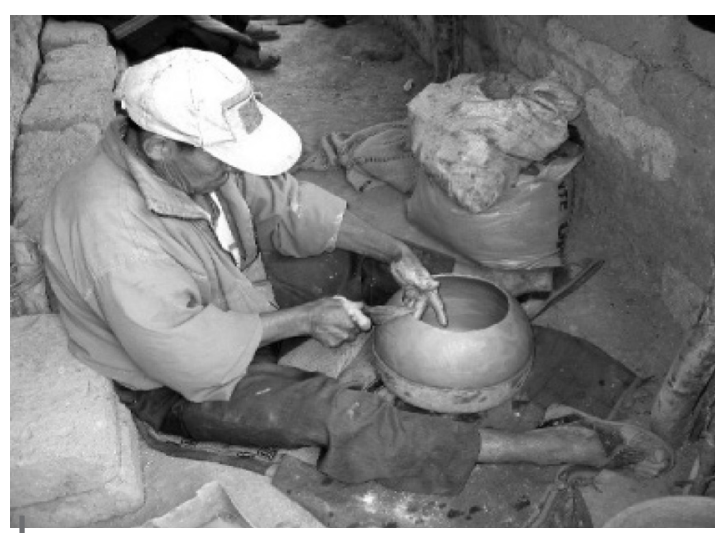

Figura 13 - Área de trabajo del alfarero Severiano Morantes (Rumichaca, Huarmaca)

Foto: Martha Bell

Para contrastar, debe mencionarse la diversidad ambiental interna y sus consecuencias. La sierra piurana ha sido dividida por niveles: ribereño (600-1 $200 \mathrm{~m})$, quichua (hasta 2500 m) y jalca (Bernex \& Revesz, 1988: 81; Correa, 1995). Cada uno vinculado a distintos cultivos, promueve el intercambio de productos entre sus habitantes. A largo plazo, esta combinación de segregación e interacción localizada explica la particular «estagnación» de ciertas técnicas, como las agrícolas (Etesse, 1991). Los alfareros no han sido insensibles a este panorama (fig. 13)31.

\footnotetext{
28 La descripción de una quema puede consultarse en Salazar et al. (1993).

29 Hasta la década de 1950, los olleros llevaban sus productos hasta Santa Cruz (Cajamarca). Al iniciar los años de 1980, los simbileños estaban preocupados por las vasijas morropanas que llegaban a Catacaos (La Industria, 21/10/1984; Camino, 1982: 94; Sabogal, 1982, I: 183; CEICAD, 1986: 52-53).

30 Registros pluviales fueron documentados en los años de 1963 a 1983 (Bernex \& Revesz, 1988: 59, 62-63) y entre 1973 y 1991 (DEPECHP, 1992).

31 En la sierra, hemos entrevistado mínimo a 5 alfareros, en detalle, por pueblo (ver Anexo 1).
} 


\section{1. Santa Ana de Huarmaca}

Este distrito al sureste de Huancabamba, está más vinculado a Cajamarca y Lambayeque, que al resto de Piura. Aunque a solo 4 horas en auto de Olmos, el clima del pueblo (2 $163 \mathrm{~m}, 1184 \mathrm{~h}$ ) es totalmente distinto. El distrito tiene las tres divisiones ecológicas citadas y existe intercambio de productos entre caseríos en ferias locales y en el mercado dominical del pueblo. Este es el único asentamiento urbano grande del distrito, pero la mayoría de la población —artesanos incluidos - reside en los caseríos.

La alfarería es oficio masculino, ejercido en la estación seca (mayo-diciembre) y siempre alternado con otras actividades32. El momento óptimo para hacer ollas es después de la cosecha (fines de julio) cuando hay más productos disponibles y, antes de las celebraciones como la del señor de la Exaltación (14 de setiembre), en cuya feria miles de campesinos Ilegan a Huarmaca (pueblo). Sabogal (1982, I: 90) registró 61 alfareros: Cuchupampa (35), Yamalán (20) y Collonayuc (6). Es riesgoso brindar un número preciso: identificamos alfareros en Yumbe, Yamalán, Rumichaca, Collonayuq, Cuchupampa, Succhupampa y Tallarán Alto. Durante la fiesta (2004), vasijas de Cedro, San Isidro, Parguyuc y Hierba Buena eran vendidas en el pueblo.

Severiano Morantes (69) es de los pocos olleros activos en la parte alta del caserío de Rumichaca ( $480 \mathrm{~m}, 05^{\circ} 35^{\prime} 55 \mathrm{~S}, 79^{\circ} 32^{\prime} 20 \mathrm{O}, 391 \mathrm{~h}$ ) a 50 minutos de Huarmaca. Como la mayoría de sus colegas, extrae la arcilla de Chalpa (Horconería), proceso que implica un día entero. La mezcla o complemento varía según el caserío del alfarero. Severiano la obtiene en Cucho, a media hora33.

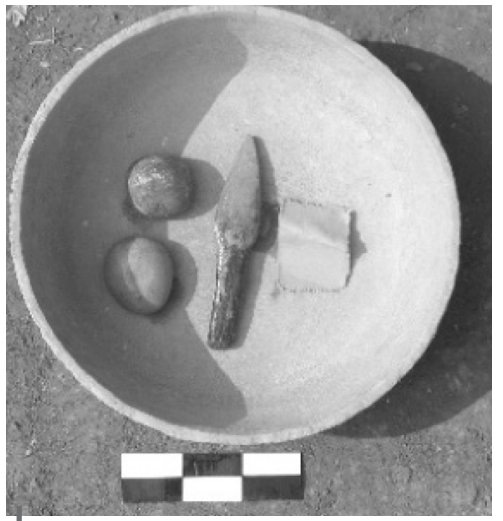

Figura 14 - Herramientas: piedras de pulir, caillua y tela en el molde

Escala: $15 \mathrm{~cm}$

- Herramientas (fig. 14). El molde es hecho por los alfareros y sus dimensiones varían, no tanto su forma: como un plato hondo, de base plana y paredes rectas inclinadas, menores al radio. Suele incluir una marca en la base interior que identifica al dueño. La caillua [callhua o cucharita] de madera varía en el distrito. La mayoría son como las de Severiano: una forma almendrada con mango ${ }^{34}$. Tiene una docena de moldes, una caillua, dos piedras de pulir, un pedazo de tela y una vasija para la ceniza.

- Elaboración (fig. 15). Severiano trabaja junto a su casa, bajo techo. Comienza espolvoreando cenizas en el molde y esparce allí un trozo de arcilla, presionándolo con los dedos, hasta obtener una capa uniforme. Hace orificios superficiales en la masa, mueve todo el material excedente al centro, y lo retira. Obtenido el grosor deseado, frota la superficie con la piedra. Hace un gran rollo de pasta y lo coloca sobre la boca de la futura vasija. La variedad comienza aquí, al elaborar la pared superior. Describiré la formación de una olla. Cuando la sección superior alcanza la misma altura que la base, se deja secando para continuar con otras vasijas. Al volver a aquella, forma, nivela y suaviza la parte superior con la caillua. El molde no gira, pero

\footnotetext{
32 Registros previos pueden consultarse en Sabogal (1981; 1982, I: 86-98).

33 Salomón Torres (+) (Cuchupampa) obtenía su material del mismo lugar (Sabogal, 1982, I: 94). Variaciones en la mezcla: Severino Chinchay (Rumichaca bajo) tiene el yacimiento en su casa; Sergio Carrasco (Cuchupampa) la obtiene en su caserío. Correa (1995: 92) menciona Chalpa y Bisnaga.

34 Entre Huarmaca y Olleros se denomina callhua o caigua no solo al instrumento textil, sino también al usado por los alfareros.
} 
a veces se rota para ayudar al proceso, especialmente al final. Alcanzado el espesor adecuado en la sección superior, le da forma redondeada trabajando con la mano dentro y la caillua fuera. Puede agregar detalles como asas o el pico de las jarras. Luego de secar bajo sombra, la vasija es separada del molde y alisada con la piedra. Permanecerá en la penumbra por una semana antes de ir al fuego.
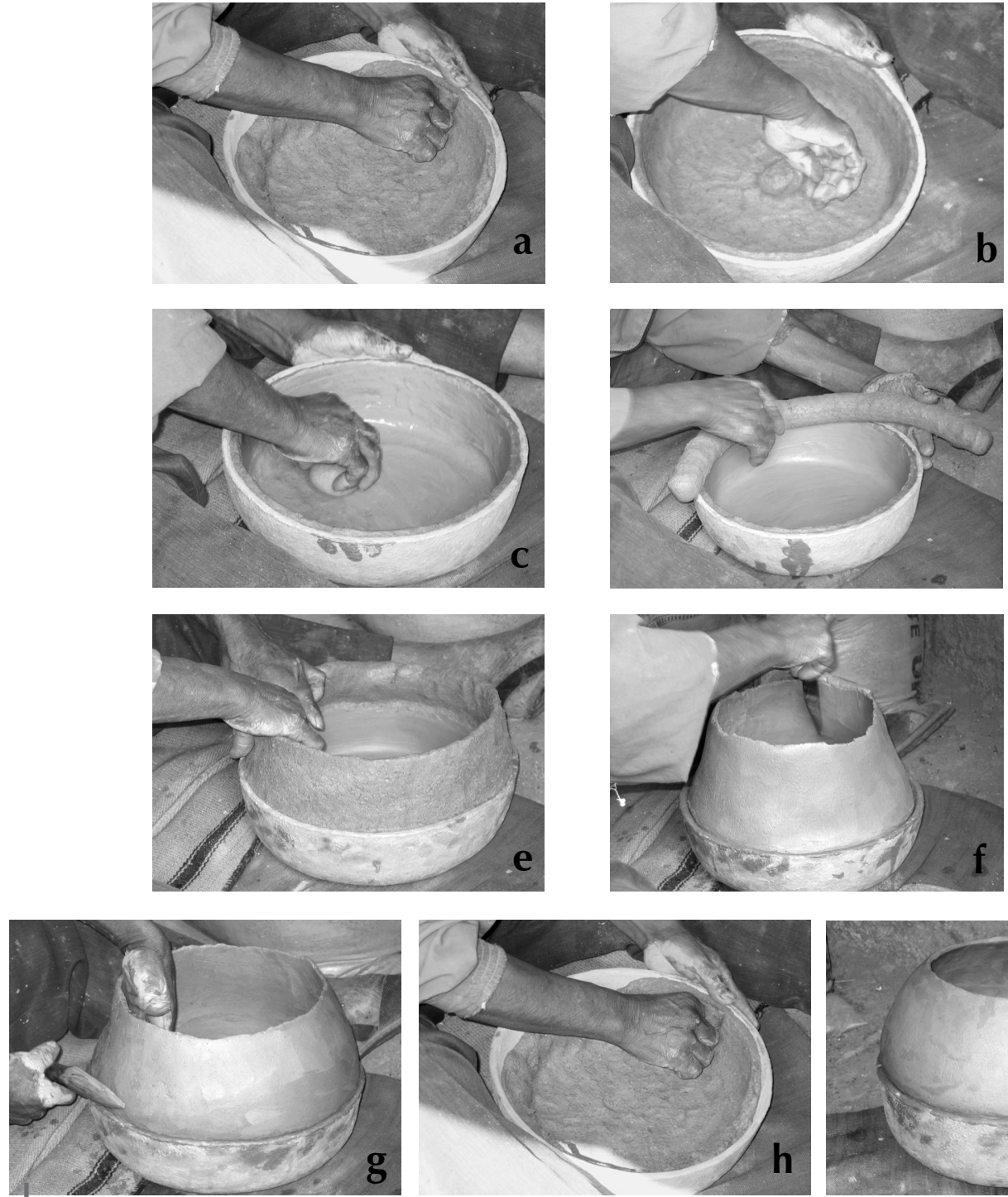

Figura 15 - Severiano Morantes (Rumichaca, Huarmaca)

a. Elaboración: Ilenando el molde; b. Nivelando la capa de arcilla; c. Uniformizando la superficie con la piedra; d. Añadiendo el rollo; e. Formando la sección superior; f. Nivelando y suavizando dentro/fuera con la caillua; g. Expandiendo el diámetro con la mano y la caillua; h. Rematando el cuello; i. Forma final secando en el molde.

Fotos: M. Bell 
Se quema en grupos chicos (ca 12) solo con estiércol (vaca, burro), ya que - Severiano afirma - la leña dañaría las vasijas. Hace tiestos o callanas [tostadores] ollas, cántaros, cazuelas, sapinas [ollas con asas], teteritas y porrones [destiladores de alcohol] (fig. 16). La producción es para uso familiar e intercambiada en el distrito de Huarmaca «a la llenada»35. En la ciudad, las vasijas suelen venderse.

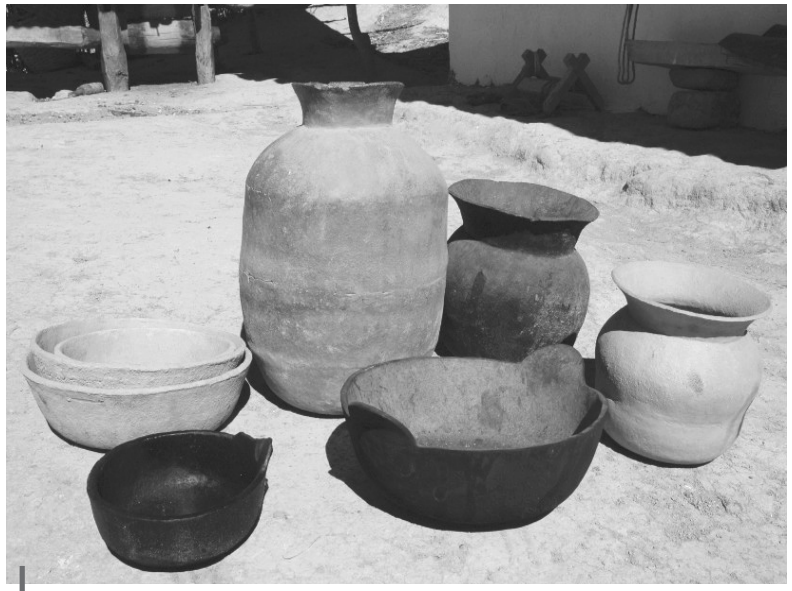

Figura 16 - Huarmaca

Sentido horario, desde abajo a la izquierda: cazuelita (negra), moldes (3), cántaro, olla (negra), olla, cazuela. Familia Huancas-Tineo, Rumichaca. Cf. Sabogal (1981: 30; 1982: I, 191) y Monzón (1991: 596).

\section{2. San Juan Bautista de Sondorillo}

Treinta minutos en auto desde Huancabamba, está Sondorillo, capital del distrito homónimo con 8600 personas repartidas en 32 caseríos. La capital (1 891 $\mathrm{m}, 180 \mathrm{~h})$ cuenta, apenas, con las casas alrededor de la plaza mayor y dos calles adyacentes. Este poblado y sus caseríos aledaños están cerca, pero muy elevados respecto al río, por ello el agua proviene de un reservorio de altura. Como en Huarmaca, este distrito tiene diversos niveles ecológicos y el correspondiente intercambio de productos.

Ya en la fundación de Sondorillo (1645) la «[a]sequia de los olleros» fue usada como lindero (Ramírez, 1966: 249-250). En 1885 el yacimiento de arcilla (Minapampa) fue donado a la «Cofradía de las Ánimas» y los olleros compelidos a pagar por usarlo36. La siguiente alusión a la alfarería es de etnógrafos contemporáneos, atraídos por el anaco, las tejedoras a cungalpo, los curanderos, la arquitectura doméstica o los derivados del méjico37. A 20 minutos verticales del pueblo está La Soccha (2 040 m, 05 ${ }^{\circ} 19^{\prime} 34$ S, 79²6’11 O, 500 h), el caserío con más olleros (20). Los otros viven dispersos en el pueblo y en los caseríos de La Lacte, Las Pampas, Rumicorral y Siclamache. Como en los pueblos precedentes, la alfarería es masculina.

Miguel Ricardo Mijahuanca (46) aprendió de su abuelo —Faustino Mijahuanca Huancay-, también de Soccha. Trabaja en la estación seca (mayo a diciembre), aunque algunos olleros (por ejemplo, José D. Huamán) producen permanentemente. En general, si llueve poco, los alfareros pasan menos tiempo en la chacra y hacen más vasijas38. En una mañana completa, Miguel extrae y mezcla dos tipos de arcilla (roja, blanca) de Minapampa (1 $800 \mathrm{~m}$, $\left.05^{\circ} 21^{\prime} 03 \mathrm{~S}, 79^{\circ} 25^{\prime} 00 \mathrm{O}\right)$.

35 La «llenada» es una unidad de medida: la vasija se cambia por uno o más «llenos» según el producto, la distancia la temporada, etc. Este sistema se practica en la sierra norte (Ancash, La Libertad, Lambayeque, Piura); también en Pasco (Fonseca, 1973: 122-124), Lima (Ramón, 1999: 239) y Cuzco (Mohr, 1984-1985: 182-183). No rige en la costa ni las urbes.

36 La cantera sigue vigente y muchos ascendientes de alfareros actuales son mencionados en el documento (1885), que nos fue gentilmente mostrado por Miguel Ludeña, tesorero de la cofradía (Sondorillo).

37 Sobre alfarería: Sabogal (1978: 11-22); Camino (1989); Muñinco (1991). Sobre las otras artesanías, ver además Ramírez (1966: 294-297); Camino (1992).

38 Comparando nuestras visitas (2004: 2005; 2006): en la primera hubo sequía y casi todos los alfareros estaban haciendo ollas, en las dos últimas la situación agrícola mejoró y hubo menos alfareros activos. 
- Herramientas (fig. 17) .Los variados moldes (19) de Miguel están repartidos por todo su taller junto a su casa. Son pares: la base, parecida a la herramienta principal de Huarmaca, aunque con el fondo redondeado, como un cuenco, y la parte superior, con un forado central (fig. 18). Cada par tiene una marca para asociarlos. El molde más común es para ollas medianas, y sirve también para jarras. Se usa la callhua [o llicu] de madera, como la hoja de un cuchillo rectangular; el canto rodado de alisar (recogido por su abuelo en la costa), otro para bruñir; un pedazo de tela o cuero, y un fragmento de cuchillo.

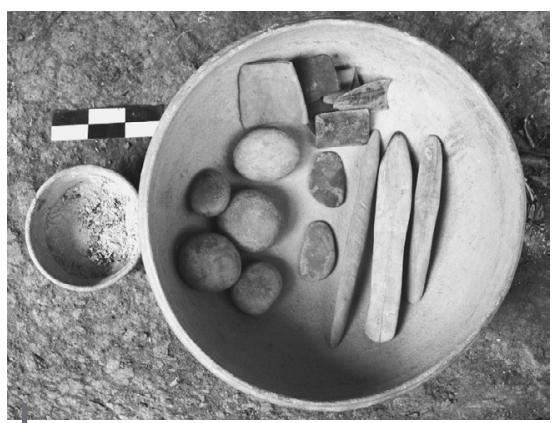

Figura 17 - Herramientas de V. Tocto

Recipiente de ceniza. Dentro del molde: cantos rodados, piedras planas, pedazos de tela $y$ cuero, callhuas. Escala: $15 \mathrm{~cm}$

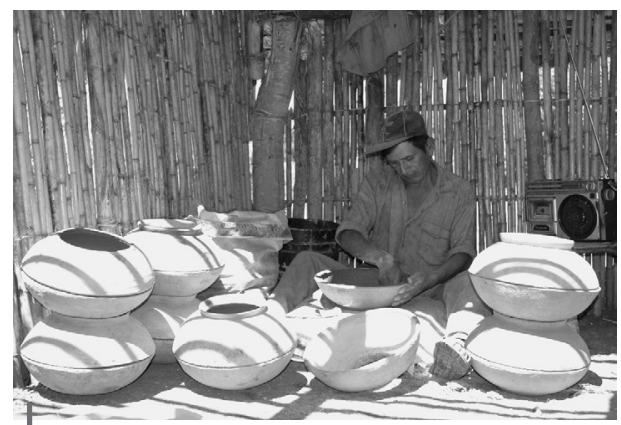

Figura 18 - Taller de Miguel Ricardo Mijahuanca (La Soccha, Sondorillo)

- Elaboración (fig. 19). Trabaja sentado en el suelo, con una base rectangular cubierta por un saco plástico, entre las piernas. Comienza espolvoreando cenizas en la base del molde y llenándolo de arcilla: expandiendo un trozo, presionando la arcilla con sus nudillos, hace hoyos regulares con los dedos para medir el grosor y uniformidad de la capa. Alisa y compacta la masa con el canto rodado, y moja frecuentemente las herramientas. Mientras la base descansa, realiza el mismo proceso con el molde superior. Cuando las dos partes están listas, las une, agregando arcilla al medio, presionando el borde con los dedos, alisando la superficie con la piedra y la tela. La futura vasija, aún en los moldes reposa mientras avanza con otras. Luego de secar, la parte superior se retira y comienza el tercer paso [golletear]. Corta el exceso de arcilla alrededor de la boca con el cuchillo, y alisa la superficie con la piedra y los dedos. Hace un rollo grande y lo adhiere a la boca. Sigue alisando la superficie externa, y con el cuero y la callhua expande el diámetro y forma el cuello. Puede agregar detalles como «falsas asas» o diseños incisos simples. Tras un día al sol, retira el molde-base y la vasija es bruñida con la piedra, generalmente por las mujeres.

Miguel quema en una superficie plana cerca de su casa, aunque otros alfareros (Julio y Francisco Manchay) tienen un área de quema especial: una gran oquedad rodeada por una empalizada. Las vasijas van sobre y cubiertas por leña (sauce, maguey). Las formas principales son ollas de diversos tamaños, tiestos, botijas, cazuelas, entre otros (fig. 20). Las vasijas se cambian «a la llenada» en caseríos y pueblos aledaños (Sondor, Huancabamba) y distantes (norte de Huarmaca). Tienen el mayor radio de distribución entre los alfareros serranos de Piura. Ha existido una relación particular con un pueblo ganadero (Palo Blanco, Ayabaca). Durante una quema (2004), Julio Manchay nos contó que la mayor parte de las 200 vasijas iba a ser para los «paloblanco» quienes venden un toro anualmente y van a La Soccha a comprar vasijas e intercambiarlas en la sierra sur de Ayabaca y al este de Morropón (Sabogal, 1978: 11, 16). 

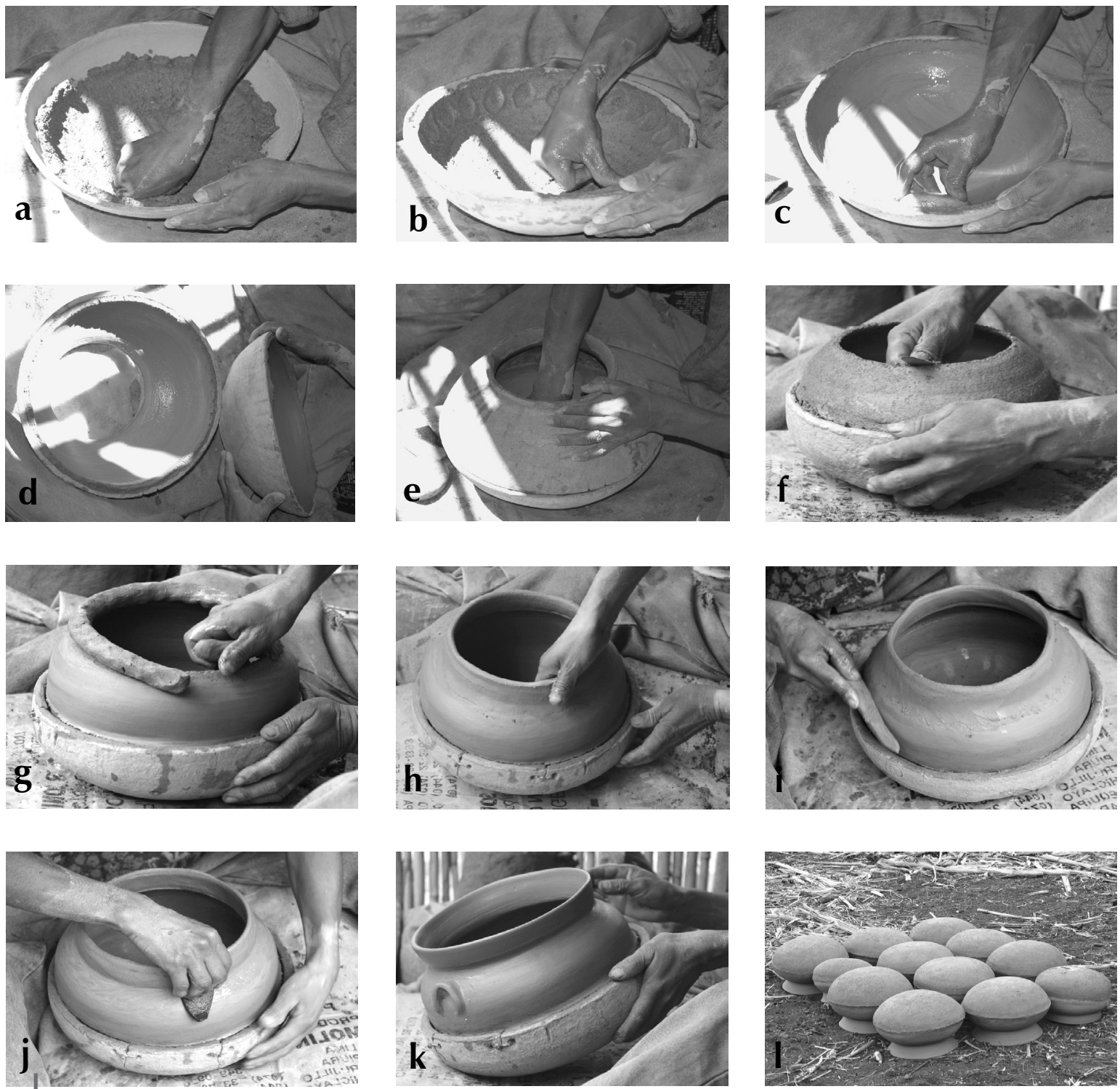

Figura 19 - Miguel Ricardo Mijahuanca (La Soccha, Sondorillo)

a-b. Elaboración: Ilenando y uniformizando la arcilla en el molde-base; c. Nivelando (canto rodado); d-e. Uniendo los moldes llenos; f. Cortando excesos (cuchillo); g. Adhiriendo el rollo; h. Formando el cuello (tela); i. Alisando el exterior (callhua); j. Ampliando el cuello (cuero); k. Añadiendo «falsas asas»; I. Vasijas secando antes del bruñido. 


\section{3. Santo Domingo}

Este pueblo (1 $484 \mathrm{~m}, 1027 \mathrm{~h}$ ) queda a cuatro horas de Morropón, en auto. Sus alrededores son irrigados por las cabeceras del río Piura que proveen de suelos útiles para la agricultura. Santo Domingo pertenece al distrito homónimo con 23 caseríos. Como en los casos previos la altitud de la zona es variable (500-3 $400 \mathrm{~m}$ ), promoviendo el intercambio de productos.

En Santo Domingo la alfarería se ha practicado en los caseríos de Yumbe, San Miguel, El Palto, Tiñarumbe, San Francisco, Simirís, Cabrería, Chacayo, Chungayo, San Agustín y Quinchayo Grande39. Hoy - en comparación con Sondorillo- la alfarería es esporádica. El oficio es femenino y las olleras viven dispersas alrededor del pueblo, y cerca de los distritos de Chalaco y Frías. Es difícil encontrarlas trabajando a diario. Los hombres suelen auxiliar en parte del proceso 40 . Aquí -y en San Bartolomé-

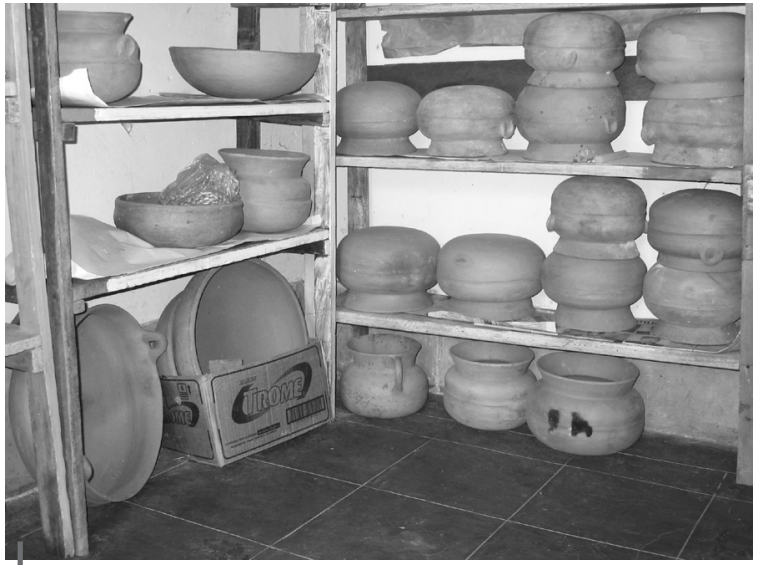

Figura 20 - Sondorillo

Ollas (algunas con «falsas asas»), jarra (con asa) en el suelo, cazuelas (una grande con asas en el suelo, otras en la caja; chicas, arriba). Vasijas de Sondorillo a la venta en Sondor (Cf. Camino, 1989: 27 fig.) usan el peonaje: una persona paga (con productos o dinero) a otra para hacer ollas juntas en su casa. Las mujeres trabajan en el telar y participan en la agricultura. Dominga Córdova (42) vive en San Miguel ( $\left.1551 \mathrm{~m}, 05^{\circ} 01^{\prime} 46 \mathrm{~S}, 079^{\circ} 51^{\prime} 12 \mathrm{O}, 444 \mathrm{~h}\right)$ a 20 minutos de Santo Domingo. Ella hace ollas en la estación seca (julio-diciembre), al menos dos veces al mes, en grupos chicos (ca 12). Su marido ayuda haciendo los rollos y recolecta y procesa la arcilla, que extrae de un yacimiento familiar a siete minutos (La Encajonada, $1528 \mathrm{~m}, 05^{\circ} 01^{\circ} 41 \mathrm{~S}$, $079^{\circ} 51^{\prime} 13$ O). Cada caserío visitado tenía su propia fuente de arcilla adyacente.

- Herramientas (fig. 21). En Santo Domingo, la herramienta central es la más versátil de Piura. Usan un mate, un plato (de metal, plástico o arcilla) y/o cualquier base equivalente rellena con ceniza, y cubierta con un trozo de hoja de plátano. Lo llaman molde y Dominga tiene seis. Utiliza dos cuchillos: uno largo [misha] y la hoja de uno menor. No pueden ser de cocina ya que — aseguran — la sal arruina la arcilla. Finalmente, usa un pedazo de mate que ella ha reemplazado por una cuchara sin mango.

- Elaboración (fig. 22). Dominga trabaja en la parte trasera de su casa, bajo techo. Como sus colegas, hace diferentes formas simultáneamente, en grupos reducidos (3-6). Para elaborar una olla, se sienta en el piso y forma la tortilla de primer asiento que sirve para cualquier forma, solo cambiando de tamaño. La expande sobre el molde. Irá añadiendo rollos que miden la mitad de la circunferencia de la vasija y por tanto trabajan en pares. Usa cuatro pares para hacer una olla. Cada uno es fijado, presionado y moldeado. Cuando todos los rollos han sido adheridos, los instrumentos entran en acción. La superficie externa se regulariza con la misha. Luego, se pasa la cuchara por el interior, expandiendo

39 Córdova (en Sabogal, 1982, II: 18) agrega dos caseríos (Batanes, Ñoma). Solo incluyo aquellos previamente registrados y que ya visitamos (Palto, San Miguel y Yumbe).

40 Estudios previos muestran que la producción alfarera de estos distritos es similar, por ello escogimos Santo Domingo. El reporte más completo es de Córdova (en Sabogal, 1982: II,17-90). Para Frías y Chalaco, ver Sabogal (1982, I: 99-118). Fotos comparativas en Sabogal (1982): Frías, El Común (I: 206-207), Pampa Grande (I: 204-205); Chalaco, Cabuyal (I: 208-209); Santo Domingo: Yumbe (II: 166-168) y un caserío no identificado (II: 163-165). Un contraste con la costa en Camino (1982: 92-93, 106-108). 
el diámetro de la vasija. El cuchillo chico corta el sobrante de arcilla de la parte superior, definiendo la boca. Finalmente, coloca asas. Varias olleras agregan un rollo para crear una banda decorativa y estructural alrededor del cuello, rasgo típico de la zona.

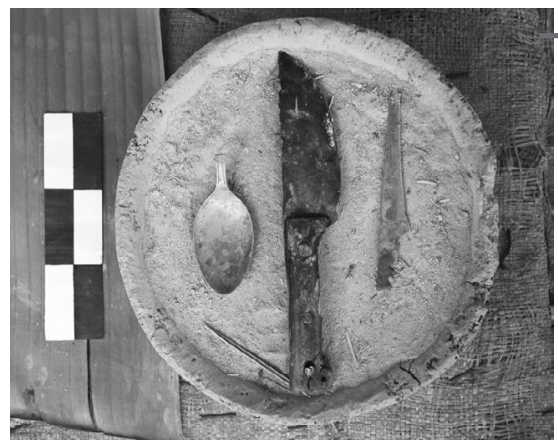

Figura 21 - Herramientas: cuchara, cuchillo grande [misha], cuchillo chico, en el mate-plato con cenizas Escala: $15 \mathrm{~cm}$
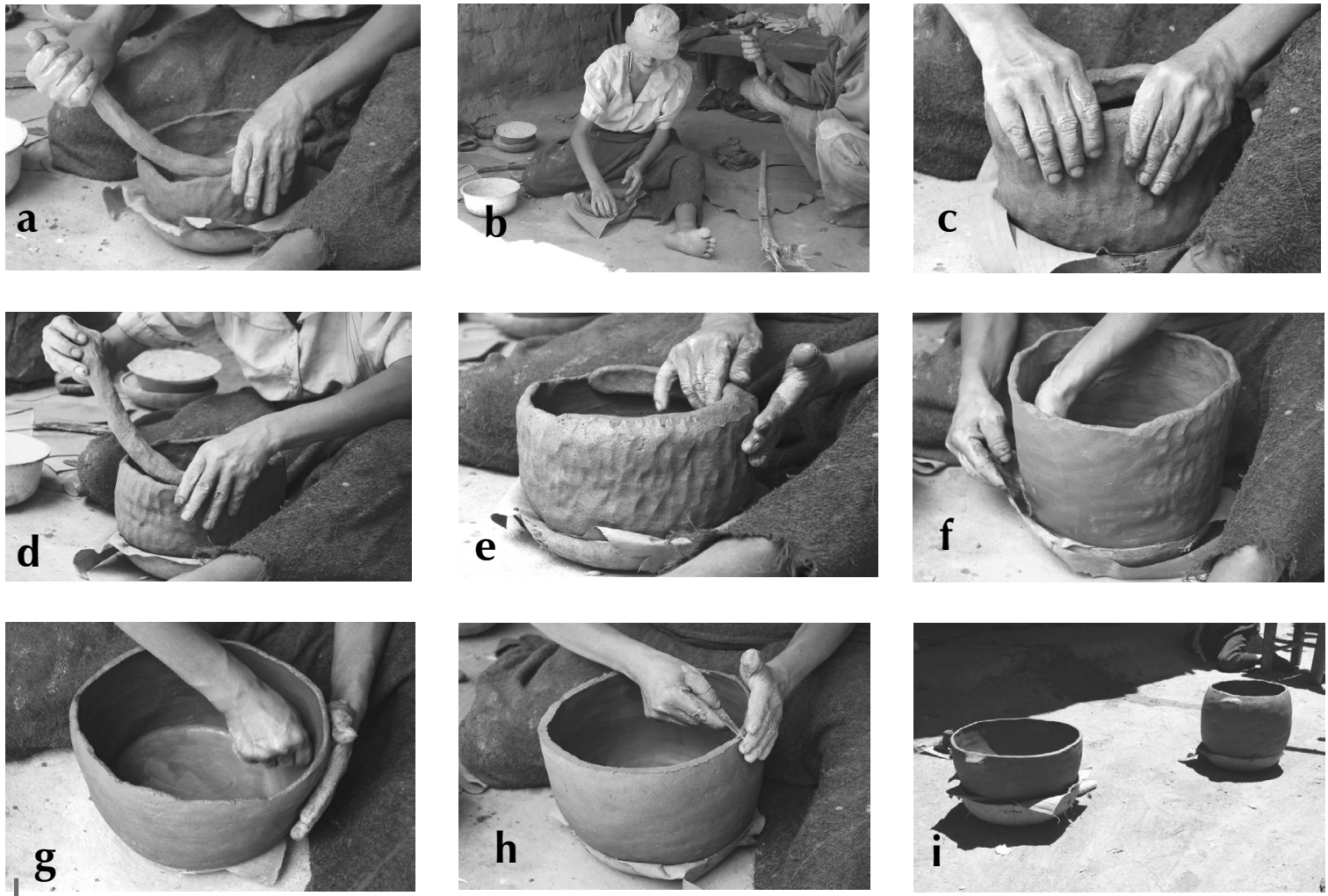

Figura 22 - Dominga Córdova (San Miguel, Santo Domingo)

a. Elaboración: presionando el primer rollo; b-c. Añadiendo, fijando y expandiendo el segundo rollo; d-e. El mismo proceso con el tercer rollo; f. Uniformizando el exterior con la mischa; g. Afinando el interior y expandiendo el diámetro con la cuchara; h. Formando el borde con el cuchillo; i. Vasijas secando. 
Luego de secar un par de días (sol, sombra) las vasijas se queman en cualquier superficie plana del patio, en grupos pequeños [yungos] (ca 12) con estiércol de res. Hace ollas, cazuelas, cántaros, asadores y especialmente tiestos o tostadoras para café y tortillas (fig. 23). La base del tiesto es plana pero la de su equivalente metálico —el perol_ es curva, siendo formas difíciles de reemplazar. El área de distribución es local (la menor de Piura) e intercambian con parientes, amigos y en caseríos aledaños de su distrito.

\section{4. San Bartolomé de los Olleros}

Esta comunidad dista cuatro horas en auto - cinco a pie, gracias a un atajo-, de la ciudad de Ayabaca (2 600 m, 3333 h). Frente a Olleros, en una cima, está Aypate, monumental sitio inca parcialmente ubicado en su jurisdicción. Durante el s. XIX, las tierras próximas de Ollería eran una comunidad indígena y Olleros pertenecía a la hacienda homónima. Tras la Reforma Agraria, la tierra de la hacienda fue distribuida entre los campesinos. Su designación [Olleros] es un indicio para rastrear la actividad en el pasado: los registros sobre la hacienda se remontan a 1621 (Schlüpmann, 1994, I: 259) y dos décadas después se alude a la actividad alfarera 41 . Rodeada por altas montañas al sureste y la frontera ecuatoriana al norte, esta técnica es virtualmente desconocida 42 .

La comunidad se divide en caseríos (Aguayco, Congolí, Sidro, Toronche, Cafetal, La Pampa), con alfareras en los dos últimos 33 . La actividad es femenina, ejercida entre mayo y diciembre. También importante es la producción de dulce y cañazo. Como en los pueblos serranos ya tratados, las mujeres usan telar de cintura [cungalpo] y ayudan en las tareas agrícolas.
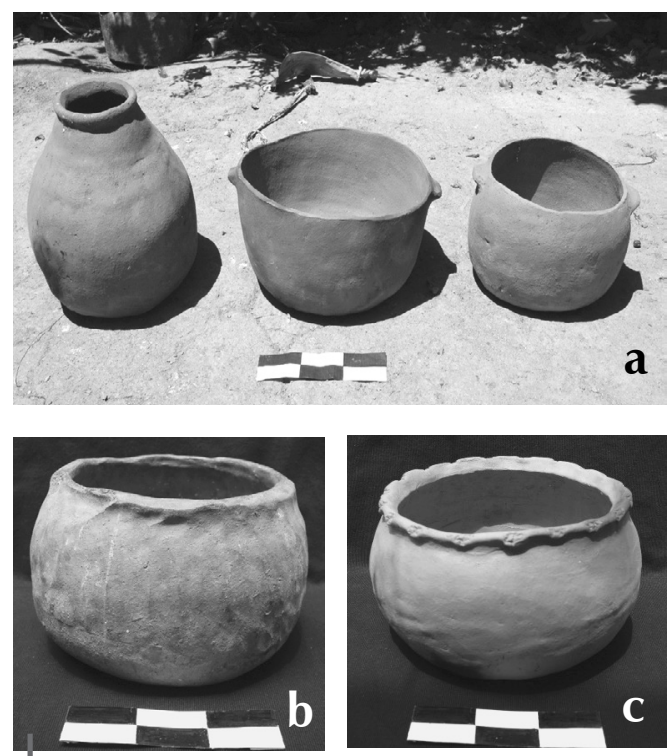

Figura 23 - Santo Domingo

a. Cántaro, olla, olla (Dominga Córdova, San Miguel)

b. Olla (Andrea López, Yumpe)

c. Olla (Pancha Rojas, Palto Alto)

Escala: 15 cm. Cf. Sabogal (1982, I: 205-209; II: 166-167)

Cafetal ( $\left.1546 \mathrm{~m}, 4^{\circ} 42^{\prime} 58 \mathrm{~S}, 79^{\circ} 37^{\prime} 28 \mathrm{O}, 350 \mathrm{~h}\right)$ está en un estrecho valle de jungla alta. Hortensia Criollo (50) vive en el centro y su taller (una empalizada de caña) está frente a su casa. La arcilla comunal está en un corral junto al cementerio (la inverna del Molino, $1507 \mathrm{~m}, 04^{\circ} 42^{\prime} 36 \mathrm{~S}, 7^{\circ} 37^{\prime} 47 \mathrm{O}$ ), a 15 minutos. Allí hay tres variedades (púrpura fino, amarillo grueso, amarillo fino) que se mezclan y amasan con el garrote de madera [macho de majar].

41 Un documento de 1645 reproduce un litigio (1817) entre la comunidad (Ollería) y la hacienda. La descripción del área reza: «tierras en que [los indios] tenian sus Oyerias» (Archivo Regional de Piura, Intendencia. Causas Ordinarias, L54, E987: 5r). Hay pueblos llamados Olleros en: Chachapoyas (San Miguel), Lima (Santo Domingo) y Ancash. El segundo tiene alfareras — al menos— desde el s. XVII (Ramón, 1999). Hubo actividad en el último siglo (Raimondi, 1873: 57, Censo, 1878, I: 161). Junto a San Miguel, en Huancas, hubo - y hay- olleras (Censo, 1878, I: 602, Chirinos et al., 2005). Al fundar ciudades coloniales, al nombre local se sumaba el del santo patrón. En casos como $\mathrm{S}$. B. de los Olleros, cuyo apéndice es un oficio: ya se practicaba en el mismo lugar antes del bautizo; en caso contrario, los alfareros de localidades vecinas fueron reducidos allí (Ramón, 1999: 220-221; Spurling, 1992: 273).

42 Castro-Pozo (1924: 299) cita la actividad, Sabogal (1978: 4-11; 1982, I: 119-131) la reporta desde Ayabaca.

43 Ollería es una comunidad aparte, sin producción alfarera. 


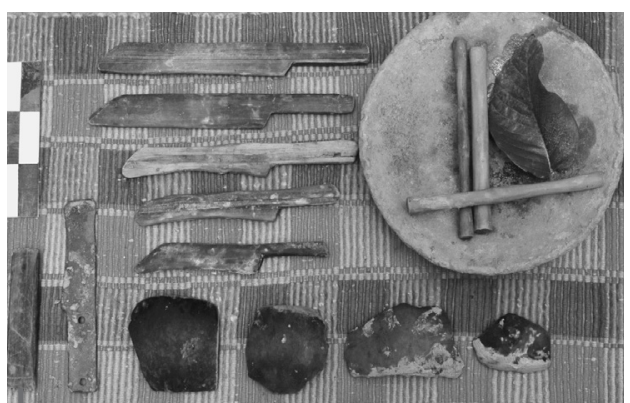

Figura 24 - Herramientas: caiguas (5), mates (4), cuchillo de fierro, labor, y en el plato de alfarero: palitos alisadores (3) y hoja de chirimoyo.

Escala: $15 \mathrm{~cm}$

- Herramientas (fig. 24). Los platos alfareros (21) de diversas dimensiones son las herramientas principales de Hortensia. Suelen incluir sus iniciales, de modo que al prestarlos a sus colegas no se pierdan44. Usa además: 5 caiguas [callhua] de madera en forma de cuchillos largos, con el mango más delgado que la hoja, palitos alisadores, pedazos de mate, medio cuchillo de acero, hojas de chirimoyo o café, y una labor de madera, para decorar.

- Elaboración (fig. 25). Hortensia hace ollas sentada en el suelo, doblando las piernas, que cubre con una alforja vieja o tela. El levantado se hace solo con las manos y el plato alfarero $(25 \mathrm{~cm} \varnothing, 1,1 \mathrm{~cm} \mathrm{~g}, 3,5 \mathrm{~cm}$ al), que rotará todo el proceso. Empolva el plato y hace una tortilla de barro que coloca sobre el primero, la expande con los dedos y le añade un rollo. Las paredes se crean por presión digital. El proceso se repetirá (rollo más presión) un par de veces más hasta obtener la altura deseada. Raspa por fuera con la caigua para regularizar la superficie externa. En el segundo paso [sacar la pancita], raspa con el mate dentro de la vasija y expande su diámetro. El resultado es una vasija sin cuello, que secará mientras avanza con el resto. En el tercer paso [voltear el filo], un rollo grueso se agrega con presión digital y regulariza el exterior con la caigua. Forma el cuello con los dedos, las hojas de chirimoyo y el palito alisador. En el próximo paso [sacar del molde], separa la base de la vasija del plato con el cuchillo y alisa su superficie con la caigua y el palito alisador. Se puede decorar con la labor y añadir asas.

Se quema en cualquier superficie plana cerca de la casa, sobre leña y estiércol vacuno. Se hacen ollas de varios tamaños, cazuelas, cántaros, tinajas, sapinas, tiestos (fig. 26). Las vasijas se cambian «a la llenada», mayormente con productos vegetales en los caseríos vecinos y en toda la provincia de Ayabaca (Sabogal, 1982, I: 128-130). La principal área de consumo son los caseríos de la extensa comunidad de Matalacas (entre Frías y Pacaipampa), a un día de camino. En el mercado de Ayabaca, intermediarias venden vasijas de Olleros todo el año.

\section{MOLDEANDO PATRONES (PRELIMINARES)}

Antes de discutir sus implicancias arqueológicas, definamos la diversidad y distribución de las técnicas alfareras en Piura. La serie Simbilá-Olmos-Mórrope tiene un eslabón histórico definido: Simbilá-Olmos. La relación Mórrope-Simbilá es solo formal ya que su historia se ignora. Los artesanos de estos tres lugares mezclan arcilla y arena y comparten el modo de quema. Principalmente producen vasijas para preparar comida y chicha, y almacenar o transportar líquidos. En cuanto a la técnica alfarera, los alfareros de Simbilá y Olmos usan al menos dos tipos de paletas (madera) y yunques (piedra). En Mórrope, emplean una paleta menos pesada (relativamente más delgada) con incisiones en un lado, mazos, el molde convexo y el parador. Estas diferencias en el conjunto de herramientas se vinculan a las particularidades formales de los productos.

44 Al plato alfarero lo llaman «molde». Mantengo el primer nombre para enfatizar la diferencia con los otros lugares mencionados, que usan moldes. El plato alfarero de Olleros es llano, ligeramente cóncavo al centro, lo que le permite girar fácilmente. Entre Cuzco y Ancash, esta forma (de menores dimensiones) se llama tilla. 

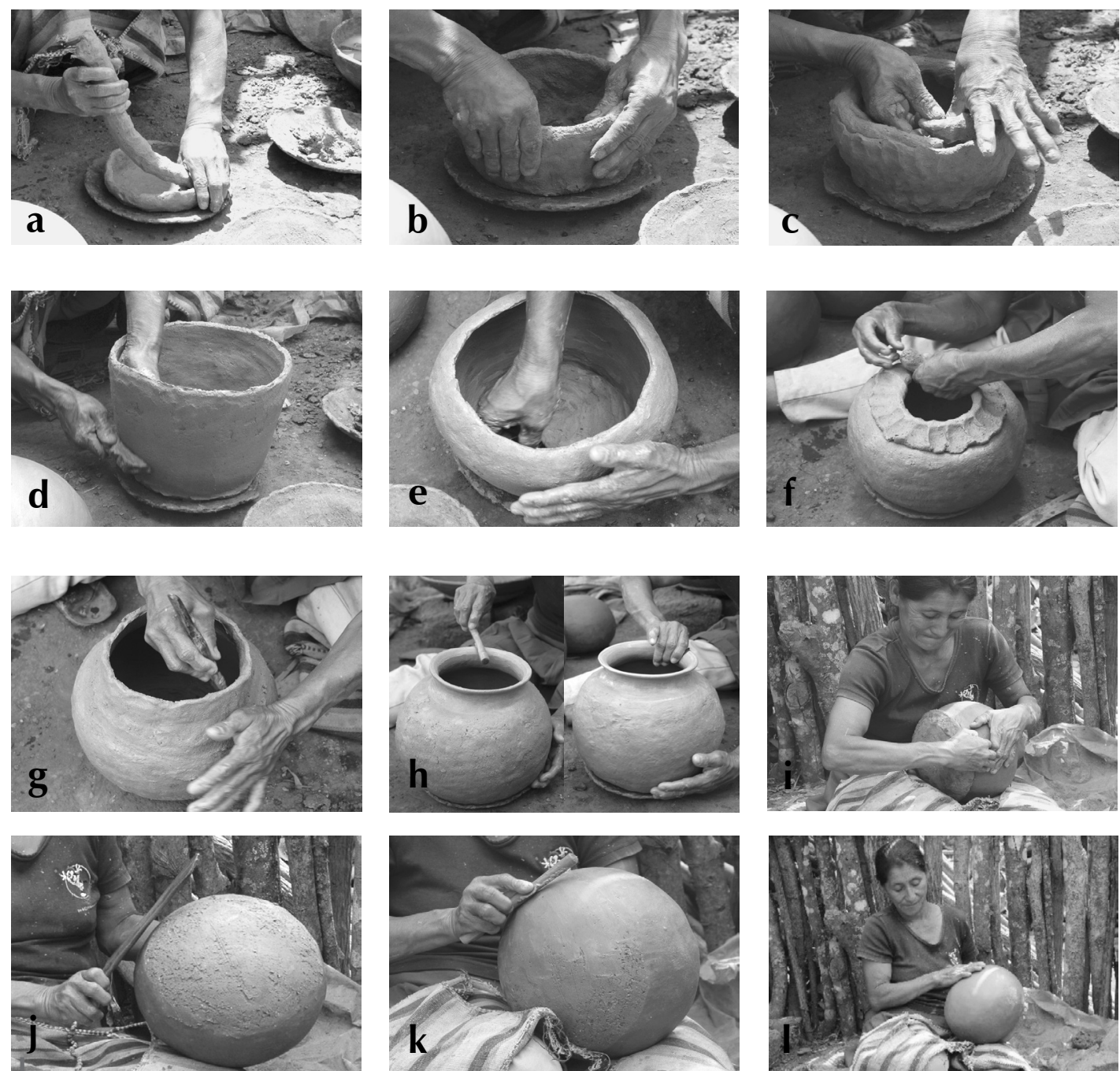

Figura 25 - Hortensia Criollo (Cafetal, San Bartolomé de los Olleros)

a. Elaboración: Añadiendo el primer rollo; b. Presionado digital; c. Añadiendo fijando y presionando el segundo rollo; d. Uniformizando el exterior con la caigua; e. Sacando la pancita; f-h. Volteando el filo; i. Separando el molde; j-k. Alisando la base con la caigua y el palito; I. Finalizando con la mano

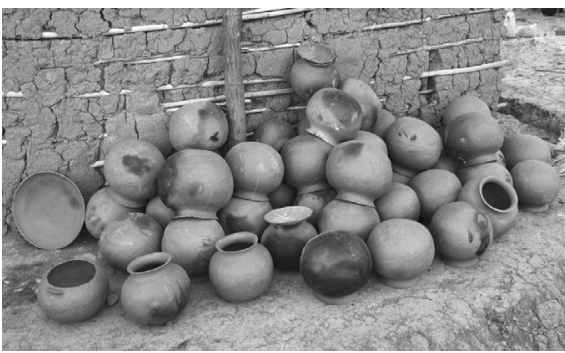

Figura 26 - Ollas -incluyendo una sapina, con asas, sin cuello- y una cazuela, ambas al extremo izquierdo (Olleros, Micaela Jiménez, La Pampa)

Cf. Sabogal (1982, I: 212-216) 
El paleteado con piedra se extiende todavía más al sur: Mangallpa (San Pablo, Cajamarca), Sinsicap y Huacaday (Otuzco, La Libertad). En los dos últimos junto con las dos herramientas principales, los alfareros usan el mazo [garrote] y rotan la vasija con los pies 45 .

En el área etnográfica del paleteado con piedra, otra técnica ha sido practicada simultáneamente: el moldeado costeño. Descrita la técnica principal de Simbilá, Scott indicaba «las formas de lujo, como cabezas humanas, efigies, frutas y formas vegetales, usadas como jarras, se hacen en secciones, en moldes de cerámica iguales a los moldes hallados en las tumbas antiguas» (1895: 21).

Este tipo de molde (cóncavo) era para figurinas y vasijas negras para turistas (Christensen, 1955; Monzón, 1991: fig. 4). La otra variedad (molde convexo) era para vasijas de cocina o jarras de chicha. Actualmente, Anita Raymundo, una de las pocas olleras simbileñas, no paletea, solo usa moldes (convexos) para hacer peroles46. Interrogados sobre los moldes, los alfareros (hombres) dijeron saber usarlos, pero no los emplean por ser «para mujeres» (Camino, 1982: 47). Un hipotético registro arqueológico simbileño —al menos del último siglodebería presentar ambas técnicas. ¿̇lndicaría esta evidencia etnográfica que la simultaneidad de técnicas distintas en un mismo contexto arqueológico puede ser interrogada en términos de género, y no necesariamente de diferencia étnica? (Arnold, 1998: 358).

En la sierra piurana hay cuatro zonas de producción, formando dos grupos: los alfareros meridionales y las alfareras septentrionales. Como un ollero de Huarmaca (J. Huancas) —que solía visitar Sondorillo- observó, ambos lugares usan técnicas similares, con la diferencia que los primeros solo tienen el molde base. Esto se evidencia en los productos. El hijo de otro alfarero huarmaquino (B. Agurto) señaló que las vasijas de Sondorillo «son más culonas». Esta diferencia de proporciones resulta de la restricción del diámetro de la sección superior por el segundo molde sondorillano. Las vasijas de este pueblo tienen una mayor área de distribución, relacionada a la actividad regular e intensiva de La Soccha, con gran número de moldes por artesano y recintos de trabajo ad hoc (talleres). Intercambian sus vasijas en los límites de otras áreas de producción alfarera como el norte de Huarmaca y Santo Domingo. En este último lugar las olleras suelen alabar la calidad de tales productos, e incluso tienen una forma local denominada sondorilla.

Entre las alfareras septentrionales hay dos variedades técnicas. En Santo Domingo, las herramientas centrales pueden reemplazarse entre sí: cambian de material, ligeramente de forma, pero no de función. El plato de plástico/metal o mate lleno de ceniza no gira con facilidad: el producto carece de la simetría obtenida por el movimiento del plato alfarero de Olleros. En Santo Domingo tienen el menor grupo de herramientas complementarias. En Olleros la herramienta principal es uniforme y posee un gran número de complementarias. Las redes de distribución de Olleros y Santo Domingo se vinculan a sus niveles productivos, siendo mucho menor en Santo Domingo, donde se apunta al consumo local o cercano. Además de la sondorilla en Santo Domingo, han usado las catacadas (o yungas) y prefieren las formas del ámbito simbileño para hacer chicha (Camino, 1982: 92-108).

Dos casos sugerirían interacción entre ambas variedades técnicas. Hace unos años, Dolores Chumacero (Santo Domingo) decidió hacer sus moldes de cerámica usando la base de sus vasijas. Son semejantes a la herramienta principal local pero no usan ceniza y sus productos son formalmente similares a los de sus paisanas. Algo análogo ocurrió con Emilia

45 Sobre Mangallpa, ver Espejo (1951). Los alfareros de Huacaday (visitados el 10/2001, 10/2004, 7/2005) tienen un vínculo documentado con Sinsicap (Camino, 1983; Campana, 1999: 120; visitado 11/2005): hace tres generaciones N. Reyes, ascendiente de una familia de olleros actuales, llegó desde Sinsicap.

46 Otras excepciones: alfareras con moldes (Chulucanas) (Sabogal (1982: I, 223-228), paleteado (Mórrope) (Bankes, 1988: 549, 557) y moldes convexos en Olmos, Mórrope y Simbilá (Litto, 1976: 16-17; Sabogal, 1982, II: 141). 
Pintado: su marido nació en Olleros, pero aprendió el oficio con su suegra. No sabe hacer platos alfareros, y usa viejos platos de metal para hacer sus ollas. Como Dolores en Santo Domingo, las vasijas de Emilia son morfológicamente típicas de Olleros.

Las técnicas serranas de Piura son más parecidas entre sí, y no tanto al paleteado costeño. Pueden definirse como una cadena (Sondorillo y Olleros a los extremos) y dos grupos de afinidad ( $\mathrm{H} / \mathrm{S}, \mathrm{SD} / \mathrm{O})$ relacionados por sexo, ubicación y ciertos rasgos formales de las herramientas principales. Olleros es a Santo Domingo, lo que Sondorillo a Huarmaca: en los dos primeros $(\mathrm{O} / \mathrm{S})$ la actividad es más intensa, el yacimiento de arcilla es uno y comunal, los conjuntos de herramientas tienen más elementos y mejor definidos, y las evidencias históricas son más tempranas. En perspectiva, en cada uno de los pueblos con alfareros visitados, herramientas, técnicas y productos forman conjuntos coherentes, son aprendidos y transmitidos entre generaciones, literalmente han sido moldeados y moldean. Los casos relatados confirman la necesidad de contar con patrones para poder identificar anomalías y narrar procesos, y de los riesgos de usar herramientas aisladas al estudiar estilos técnicos en arqueología.

\section{INERCIA RETROSPECTIVA: HALLAZGOS ETNOGRÁFICOS Y ARQUEOLOGÍA PIURANA}

Utilizar evidencia actual sobre ceramistas para entender las técnicas precoloniales, no implica —necesariamente - que asumamos una continuidad milenaria. Antes bien, este artículo se sitúa en la posición analítica contraria: la producción rural de alfarería es la más valiosa evidencia disponible para empezar a entender las técnicas precoloniales como un producto cultural. ¿Cómo podemos saber que un plato de alfarero es tal si no lo hemos visto antes en uso, o leído una explicación sobre ello? ¿Si no hemos visitado el callejón de Conchucos, podremos deducir para que sirve un tucllu? Con esto no deseo promover el turismo, sino enfatizar que sin experiencia etnográfica (vista o transmitida) no habrá diálogo interpretativo con la evidencia arqueológica. Como se mencionó al inicio, en los tratados de Shepard (1965: 54-65) y Rice (1987: 124-136), es la evidencia etnográfica la que permite explicar las técnicas alfareras - Tello (1938) para los Andes-. Tal evidencia es útil para reconocer posibles funciones y asimismo, para entender contextos de producción. Como el caso del norte peruano nos permite observar, las técnicas alfareras no están repartidas casualmente en el paisaje actual ni en el arqueológico, sino que se relacionan con la gente que las produjo y consumió. El debate sobre el uso de la evidencia etnográfica y etnohistórica para discutir el pasado precolonial no se limita a la cerámica, y sigue en pie — véase Makowski (2005: 50-52) — para las diversas tendencias en pugna respecto al análisis de las imágenes. Cualquier inventario futuro sobre técnicas alfareras precoloniales no puede ignorar la variabilidad documentada en el presente, especialmente porque las discusiones previas en arqueología andina están enraizadas en tal experiencia etnográfica, como sucede en el caso piurano.

Siete décadas después de las excavaciones de Scott, apareció la primera secuencia alfarera piurana (Lanning, 1963). Desde el Periodo Inicial (ca 1800 a.n.e.) hasta el presente, la alfarería costeña fue clasificada en cinco estilos, divididos en fases. El último, Simbilá, equivalente a la era republicana, se basó en cuatro tiestos de un basural sechurano, una olla simbileña y un informe etnográfico (Christensen, 1955). Esta es aún la secuencia canónica para clasificar la cerámica piurana47. Lanning propuso este marcador cronoestilístico

47 La secuencia de Lanning es costeña, pero no hay nada parecido para la sierra (Kelley, 1965; Richardson et al., 1990; Guffroy et al., 1989). 
aplicando la «seriación por semejanza» (Rowe, 1959). Peculiar en su secuencia, fue el énfasis en la técnica constructiva como rasgo clasificatorio. Al discutir aquella del estilo Sechura (ca 100 a.n.e.- 600 n.e.) usando las huellas de las herramientas, sugería que en el mismo proceso los alfareros podrían haber paleteado las vasijas después del enrollado. Pero enseguida retrucaba:

«No obstante, los alfareros actuales de Simbilá hacen sus vasijas enteramente con la paleta y el yunque e ignoran el enrollado. Ya que las técnicas de Simbilá representan una continuación de las antiguas tradiciones, no hay razón para asumir que un método distinto fue usado en la alfarería arqueológica paleteada» (Lanning, 1963: 166; original no subrayado).

Este razonamiento circular es más que un detalle: el cambio principal de la secuencia cerámica piurana fue el paso de vasijas «solo enrolladas» (Negritos-Sechura B) a «solo paleteadas» (Sechura D-Simbilá) (cuadro 1). La secuencia arqueológica piurana se basa en evidencia etnográfica, especialmente en una técnica simbileña.

Establecida su cronología, Lanning aludía a la geografía de las técnicas, discutiendo el área original y la distribución regional del paleteado y el moldeado. Collier (1959: 428-429) ya había distinguido entre dos áreas técnicas precoloniales: el paleteado del litoral extremo norte (relacionado al ámbito Mórrope-Simbilá), y el uso del molde de una y dos piezas cóncavas de la costa de La Libertad y parte de la de Ancash, relacionado al estilo decorativo moche. Años antes, Larco (2001 [1938-1939]) había intentado explicar la técnica alfarera moche, recurriendo a un caso etnográfico de la sierra liberteña (El Alto, Mollepata) donde se usaba doble molde vertical y decorado. A mediados de siglo, la distribución de las técnicas precoloniales replicaba la evidencia publicada por los etnógrafos. La geografía técnica propuesta por Collier fue seguida por Lanning (1963: 209) y los arqueólogos más recientes (Schaedel, 1979; Cleland \& Shimada, 1994). Ya que las discusiones etnográficas, y arqueológicas, sobre identidad étnica tienen al estilo técnico como base (Gosselain, 2002), este es aún el estado de la cuestión para el extremo norte peruano.

\section{Cuadro 1 - Técnicas alfareras de la región Piura-Chira}

Las líneas continuas indican la presencia del rasgo. Las letras mayúsculas son las fases.

Fuente: Lanning (1963: 191-197)

Estilos cerámicos

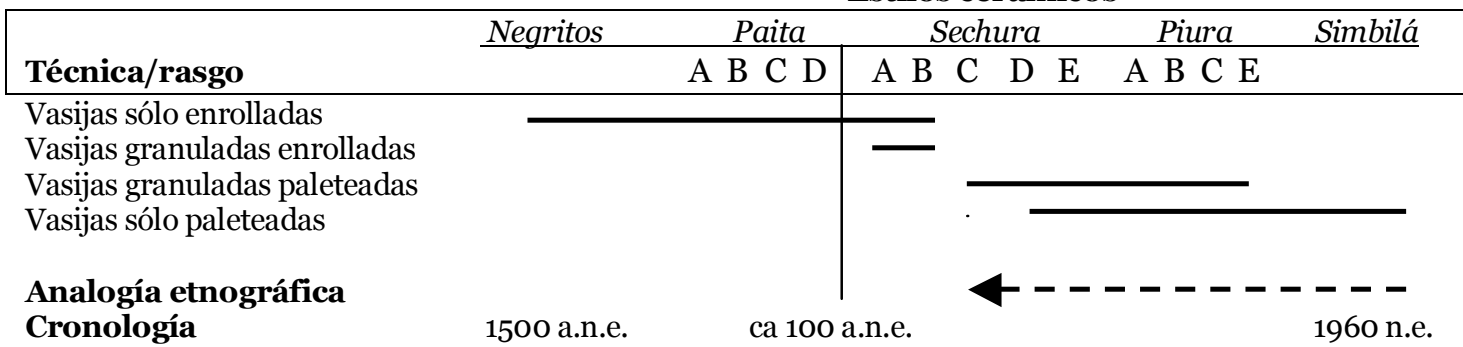


La evidencia etnográfica ha servido para generalizar los pocos ejemplos conocidos, soslayando diferencias intrarregionales. Las referencias publicadas sobre producción alfarera precolonial, particularmente herramientas, permiten caracterizar de modo preliminar los patrones regionales del norte peruano, y ayudan a identificar anomalías que sugieren procesos ignorados. Un primer caso sería la escasez de platos alfareros — comunes en el sur peruano (Mohr, 1984-1985: 166-167) — en la arqueología y etnografía norteña. Cuando este elemento aparece en contextos arqueológicos de la costa norte no es explicado (por ejemplo, la ocupación moche IV-V de Huaca de la Luna y Pampa Grande). La etnografía trajo la respuesta: la descripción de las técnicas alfareras y los patrones generales de su distribución, ipor qué no usarla para interrogar al material arqueológico? Si de acuerdo a los arqueólogos, la costa norte ha sido un territorio asociado al paleteado y al molde bivalvo, ¿qué hacen allí los platos de alfarero? (cuadro 2).

\section{Cuadro 2 - Evidencia arqueológica de producción alfarera (Andes Centrales)}

Las herramientas necesarias para definir la técnica se encuentran resaltadas en negrita.

Abreviaturas: H: Horizonte, I: Intermedio, T: Temprano, M: Medio, Ta: Tardío

\begin{tabular}{|c|c|c|c|}
\hline \multicolumn{4}{|c|}{ Norte: INTERMEDIO TeMPRANO (MOCHE) } \\
\hline Lugar & Fase & Técnica: evidencia & Fuente \\
\hline $\begin{array}{l}\text { Huaca de la } \\
\text { Luna (Moche) }\end{array}$ & IV & $\begin{array}{l}\text { moldes bivalvos (58), matrices (4), vasijas crudas } \\
(26 \text {, incluyendo } 2 \text { matrices), plato alfarero (?) }\end{array}$ & $\begin{array}{l}\text { Armas et al. (1993); Uceda \& Armas } \\
\text { (1998) }\end{array}$ \\
\hline $\begin{array}{l}\text { Pampa de los } \\
\text { Incas (Santa) }\end{array}$ & IV & Moldes & Wilson (1988: 211) \\
\hline $\begin{array}{l}\text { Cerro Mayal } \\
\text { (Chicama) }\end{array}$ & IV-V & $\begin{array}{l}\text { moldes (100), tiestos sobrecocidos, pulidores, } \\
\text { horno }\end{array}$ & $\begin{array}{l}\text { Russell et al. (1994a, 1994b); } \\
\text { Russell \& Jackson (2001) }\end{array}$ \\
\hline $\begin{array}{l}\text { Galindo } \\
\text { (Moche) }\end{array}$ & $\mathrm{V}$ & moldes, horno & Bawden (1982; 1996: 98-101) \\
\hline $\begin{array}{l}\text { Pampa Grande } \\
\text { (Lambayeque) }\end{array}$ & V & $\begin{array}{l}\text { moldes, pulidores (piedra), vasijas sin uso, } \\
\text { horno, plato alfarero (?) }\end{array}$ & Shimada (1994b: 191-200) \\
\hline
\end{tabular}

\begin{tabular}{|l|c|l|l|}
\hline \multicolumn{4}{|c|}{ Norte: Horizonte Medio A Horizonte TARDío } \\
\hline \multicolumn{1}{|c|}{ Lugar } & Periodo (estilo) & \multicolumn{1}{c|}{ Técnica: evidencia } & \multicolumn{1}{c|}{ Fuente } \\
\hline $\begin{array}{l}\text { Huaca Facho } \\
\text { Lambayeque) }\end{array}$ & $\begin{array}{l}\text { I. Tardío } \\
\text { (Chimú) }\end{array}$ & $\begin{array}{l}\text { moldes bivalvos (3 pares, 7 mitades), } \\
\text { matriz, sello }\end{array}$ & Grossman (1969-1970) \\
\hline $\begin{array}{l}\text { Pampa de Burros } \\
\text { (Lambayeque) }\end{array}$ & $\begin{array}{l}\text { I. Tardío } \\
\text { (Chimú) }\end{array}$ & $\begin{array}{l}\text { moldes de vasija asa estribo, paletas } \\
\text { decoradas, hoyo de quemar }\end{array}$ & Tschauner et al. (1994) \\
\hline $\begin{array}{l}\text { Cañoncillo } \\
\text { (Jequetepeque) }\end{array}$ & $\begin{array}{l}\text { H. Tardío } \\
\text { (Chimú-Inca) }\end{array}$ & $\begin{array}{l}\text { moldes (fragmentos, 63), tiestossobrecocidos, } \\
\text { arcilla cruda (trozos), carbón vegetal }\end{array}$ & Donnan (1997) \\
\hline $\begin{array}{l}\text { Tambo Real } \\
\text { (La Leche) }\end{array}$ & $\begin{array}{l}\text { H. Tardío } \\
\text { (Inca-Chimú) }\end{array}$ & $\begin{array}{l}\text { moldes (133), vasijascompletasnoquemadas, } \\
\text { pedazos de arcilla no quemada, ceniza }\end{array}$ & Hayashida (1995) \\
\hline $\begin{array}{l}\text { La Viña } \\
\text { (La Leche) }\end{array}$ & $\begin{array}{l}\text { H. Tardío } \\
\text { (Inca-Chimú) }\end{array}$ & $\begin{array}{l}\text { moldes (82), fragmentos de vasijas crudas, } \\
\text { conchas, hoyos con huellas de quema }\end{array}$ & Hayashida (1995) \\
\hline
\end{tabular}




\begin{tabular}{|c|c|c|c|}
\hline \multicolumn{4}{|c|}{ Centro y Sur: Horizonte Temprano a Horizonte Tardío } \\
\hline Lugar & $\begin{array}{l}\text { Periodo } \\
\text { (fase) }\end{array}$ & Técnica: evidencia & Fuente \\
\hline Paracas (Ica) & H.T. (10) & plato alfarero (con figura incisa) & $\begin{array}{l}\text { Rowe en Mohr (1984- } \\
\text { 1985: 167) }\end{array}$ \\
\hline Jauranga (Palpa) & H.T. & platos alfareros, alisadores, pulidores & $\begin{array}{l}\text { Isla et al. (2003: 266- } \\
\text { 268) }\end{array}$ \\
\hline $\begin{array}{l}\text { Tablada de Lurín } \\
\text { (Lima) }\end{array}$ & I.T. & $\begin{array}{l}\text { platos alfareros (142), trozos de arcilla } \\
\text { trabajada, piedras pulidas, valvas; asociado a } \\
\text { entierros femeninos ( } 37 \text { ) }\end{array}$ & Cárdenas (1994) \\
\hline Usaca (Nazca) & I.T. & platos alfareros (2) [?] & Isla (1992:129-130) \\
\hline Cahuachi (Nazca) & I.T. & $\begin{array}{l}\text { platos alfareros, pigmento rojo, terrones de } \\
\text { pigmento, objetos de pelo fino, espátulas }\end{array}$ & $\begin{array}{l}\text { Carmichael (1998: } \\
\text { 219); Silverman (1993: } \\
\text { 302) }\end{array}$ \\
\hline $\begin{array}{l}\text { Ingenio y valle } \\
\text { Grande (Ica) }\end{array}$ & I. T. & platos alfareros (fragmentos) & $\begin{array}{l}\text { Silverman \& Proulx } \\
(2002: 60)\end{array}$ \\
\hline Maymi (Pisco) & $\begin{array}{l}\text { H. M. } \\
\text { (inicios) }\end{array}$ & $\begin{array}{l}\text { plato alfarero, trozos de arcilla trabajada, } \\
\text { tiestos crudos, pinceles, moldes, hoyos de } \\
\text { quema }\end{array}$ & Anders et al. (1998) \\
\hline $\begin{array}{l}\text { Conchopata } \\
\text { (Ayacucho) }\end{array}$ & H. M. & $\begin{array}{l}\text { platos alfareros, moldes bivalvos, raspadores, } \\
\text { paletas líticas [?] y de cerámica [?] }\end{array}$ & $\begin{array}{l}\text { Pozzi Escot et al. } \\
\text { (1993); Cook \& Benco } \\
\text { (2000) }\end{array}$ \\
\hline $\begin{array}{l}\text { Aya Orqo } \\
\text { (Ayacucho) }\end{array}$ & H. M. & platos alfareros & $\begin{array}{l}\text { Pozzi Escot et al. } \\
(1993)\end{array}$ \\
\hline $\begin{array}{l}\text { Ayapata } \\
\text { (Huancavelica) }\end{array}$ & H. M. (2a) & plato alfarero, pulidores & $\begin{array}{l}\text { Ravines (1977: 53-54, } \\
71)\end{array}$ \\
\hline Tumba TH-1 (Ica) & $\begin{array}{l}\text { I. Ta. (Ica } \\
6)\end{array}$ & $\begin{array}{l}\text { piedra negra pulida, valva (molusco), terrones } \\
\text { de pigmento mineral rojo ( } 3 \text { ) }\end{array}$ & Menzel (1976: 31) \\
\hline $\begin{array}{l}\text { Pachacamac } \\
\text { (Lima) }\end{array}$ & I. Ta. & Moldes & Eeckhout (2003: 147) \\
\hline $\begin{array}{l}\text { Galarza, Sitio Y } \\
\text { (Ica) }\end{array}$ & $\begin{array}{l}\text { H. Ta. } \\
\text { (Ica 9/10) }\end{array}$ & plato alfarero con diseños & Menzel (1976: 31) \\
\hline Milliraya (Puno) & H. Ta. & raspadores, trozos de arcilla sin quemar & Spurling (1992) \\
\hline
\end{tabular}


Las discusiones sobre producción alfarera en el Intermedio Temprano usan evidencia limitada y asumen que hubo una técnica por varios siglos y cientos de kilómetros (Donnan, 1965; Purin, 1983a; 1983b)48. Pese a que el estilo (decorativo) moche ha sido subdivido en fases, ¿comparten ellas un mismo estilo técnico? En el área (costa norte) caracterizada por otros modos de producir (en el registro arqueológico y etnográfico), la presencia del plato de alfarero a fines del Intermedio Temprano sugiere una técnica meridional. Podría entonces plantearse un desplazamiento de herramientas de artesanos sureños justo cuando las vasijas de la costa central (estilo Nievería, Lima) comienzan a aparecer en contextos arqueológicos septentrionales (San José de Moro, Jequetepeque)49.

Para concluir, volvamos a San Bartolomé de los Olleros para sugerir una segunda hipótesis. Este es el único caso etnográfico piurano y del extremo norte peruano, donde el plato alfarero típico del sur es la herramienta principal. El lugar más próximo con una técnica similar está en la sierra limeña. Además de compartir técnica, sexo y denominación (data, al menos, del siglo XVI), son territorialmente asociados a sitios Inca (Aypate y Pachacamác). Se podría asumir que la presencia norteña y aislada de la técnica (San Bartolomé) se asocia a la instalación Inca (¿mitimaes?) y/o la ocupación colonial temprana de la sierra de Piura.

\section{Agradecimientos}

A las alfareras, los alfareros y sus familias, por su paciencia. En particular, a Francisco y Julio Manchay y familias (La Soccha), las señoras del Club de Madres (La Pampa) y Poli Chapoñán (Ollería, Mórrope). Durante el trabajo de campo en Piura (agosto-octubre 2004, julio-agosto 2005, junio 2006) aprendí de Martha Bell, Kristel Best y José Luis Pino. A George Lau, mi asesor, por su permanente auxilio. A Lupe Camino, que me animó a explorar Piura, y por su archivo personal. A Césitar Astuhuamán, George Bankes, Daniel Dávila y Bill Sillar por el material bibliográfico y sus comentarios. A Claude Chapdelaine e Isabelle Druc, por su atenta lectura crítica. Al personal del CIPCA (Piura) por atendernos con alegría, y permitirme revisar la colección fotográfica Quiroz. Todas las fotos son mías salvo indicación.

48 Una útil discusión preliminar de la relación grupos étnicos/cultura material en el Intermedio Temprano de la costa norte, puede verse en Makowski (1998).

49 Otra opción para estos anómalos platos alfareros sería un problema descriptivo (Uceda \& Armas, 1998: 97-98 Shimada, 1994b: 191-200). Incluso entonces, la evidencia etnográfica es precisa para sistematizar la arqueológica. Las herramientas presentes en los talleres de Maymi (Pisco) y Conchopata (Ayacucho) (ambos del Horizonte Medio) invitan a un escrutinio semejante (ver cuadro 2). En el mismo sentido cabe estudiar los platos de alfarero atribuidos a Recuay (Nepeña) (Proulx, 1973: 35, 38, 238-239). 


\section{Anexo}

\section{Alfareros serranos}

Los caseríos se presentan en mayúsculas; los entrevistados (2004-2005) aparecen resaltados en negritas; los no-alfareros, entre paréntesis, indicando su relación con los artesanos. Abreviaturas empleadas: madre, esposa/o, hija, viuda, (†): fallecido.

Santa Ana de HUARMACA

YUMPE. Briceño Agurto (m: Emperatriz Peña); Floro Agurto; Silverio Agurto; Luciano García; Salomón Torres (†) (v: Dorotea Seña); Eugenio Yajahuanca.

YAMALÁN. Agustín Carrasco; Fortunato García; Ambrosio García (e: Maruja Santos); José Quispe (e: Modesta Huamán); José Rosario Yajahuanca; Pancho Torres; Isidoro Yajahuanca (e: Filomena Chinchay); José Yajahuanca.

RUMICHACA. Segundo Chinchay; Severino Chinchay; Delfín Chuquipoma; Teodoro Chuquipoma; Apolinar Huancas; Calixto Huancas; Julio Huancas (e: Teodosia Tineo); Esmundo Morantes; Severiano Morantes (h: Yolanda M.); Armógenes Torres; Filemón Torres; Florencio Torres; Venancio Torres; Victoriano Torres.

COllonaYUQ. Venancio Arévalo (e: Antonia García); Faustino (e: Rosa de García); Pedro Quispe.

CUCHUPAMPA COLlONAYUQ. Sergio Amado Carrasco (e: Margarita Seña)

San Juan Bautista de SONDORILLO

La SOCCHA. Rafael Cruz; Lucas Farseque; Eloy Huamán; José Dolores Huamán; Julio Manchay; Francisco Manchay; Valentín Manchay; Teófilo Martínez; Miguel Ricardo Mijahuanca; Alejandro Santos; Francisco Santos; Máximo Santos ; Victorino Tocto .

SONDORILLO (Pueblo) Juan Córdova; Francisco Ríos; Sigifredo Tripul; Teodomiro Tripul.

La LACTE. Alejandro Berrios Cimbrera; Julio Berrios; José del Carmen (†); Porfirio Córdova.

RUMICORRAL. Antonio Laván.

SHAYANGO. Francisco Cimbrera; Faustino Minga Santos.

Santo DOMINGO

SAN MIGUEL. Dominga Córdova (e:Pancho Rojas); Cristina Saavedra de Chumacero.

PALTO BAJO. Guadalupe Ramírez ; Panchita Rojas.

TRIGO PAMPA. Severa Mesones

YUMBE. Dolores Chumacero; Andrea López.

LANCHE BAJO. Pola García.

San Bartolomé de los OLLEROS

CAFETAL. Josefa Abad; Eva Bermeo; Lucila Chuquihuanga; Hortensia Criollo Girón; Hermelinda Mondragón; Josefa Mondragón; Isolina Mondragón; Orfilia Mondragón (e: Mario Mondragón Parihuamán); Emilia Pintado Malacatos.

La PAMPA. Angélica Abad; Irma Abad; Altagracia Chuquiguanga; Grimanesa Huamán; Micaela Jiménez Mondragón; Rosa Jiménez; Rosa Mondragón. 


\section{Referencias citadas}

ANDERS, M., CHANG, V., TOKUDA, L., QUIROZ, S. \& SHIMADA, I., 1994 - Producción cerámica del horizonte medio temprano en Maymi (Valle de Pisco, Perú). In: Tecnología y Organización de la Producción Cerámica Prehispánica en los Andes (I. Shimada, ed.): 249-268; Lima: PUCP.

ARMAS, J., CHAMORRO, V. \& JARA, G., 1993 - Investigaciones arqueológicas en el complejo Huaca del Sol y la Luna: talleres alfareros de la sociedad Moche, 162 p.; Trujillo: Facultad de Ciencias Sociales, Universidad Nacional de Trujillo. Informe de prácticas pre-profesionales en arqueología.

ARNOLD, D., 1998 - Ancient Andean Ceramic Technology: An Ethnoarchaeological Perspective. In: Andean Ceramics: Technology, Organization, and Approaches (I. Shimada, ed.): 353-367; Philadelphia: Museum of Applied Science Center for Archaeology, University of Pennsylvania Museum of Archaeology and Anthropology.

ARNOLD, D., NEFF, H. \& GLASCOCK, M. D., 2000 - Testing assumptions of neutron activation analysis: communities, workshops and paste preparation in Yucatán, México. Archaeometry, 42: 301-316.

BANKES, G., 1985 - The manufacture and circulation of paddle and anvil pottery on the north coast of Peru. World Archaeology, 17: 269-277.

BANKES, G., 1988 - Paddle and anvil potters of the north coast of Perú. In: Recent Studies in precolumbian Archaeology (N. Saunders \& O. Montmollin, eds.): 545-564; London: BAR.

BERNEX, N. \& REVESZ, B., 1988 - Atlas Regional de Piura, 208 p.; Piura: CIPCA, PUCP.

BINGHAM, H., 1915 - Types of Machu Picchu Pottery. American Anthropologist, 17: 257-271.

BRÜNING, H., 1898 - Moderne Töpferei der Indianer Perus. Globus, 74: 259-260.

BRÜNING, H., 1922-1923 - Estudios Monográficos del Departamento de Lambayeque. Fascículos I-IV; Chiclayo: Librería e Imprenta de Dionisio Mendoza.

BRÜNING, H., 2004 - Diccionario Mochica, 135 p.; Lima: USMP.

CAMINO, L., 1982 - Los que vencieron al tiempo, 139 p.; Piura: CIPCA.

CAMINO, L., 1983 - Los últimos olleros de Sinsicap. Boletín de Lima, 29: 31-36.

CAMINO, L., 1987 - Chicha de maíz: bebida y vida del pueblo Catacaos, 103 p.; Piura: CIPCA.

CAMINO, L., 1989 - Olleros y sogueros de Sondorillo, Piura. Boletín de Lima, 61: 25-28.

CAMPANA, C., 1999 - Vicús y la alfarería norandina, 137 p.; Lima: UNFV.

CARDENAS, M., 1994 - Platos de alfarero de entierros del formativo tardío en la costa central. In: Tecnología y Organización de la Producción Cerámica Prehispánica en los Andes (I. Shimada, ed.): 173-200; Lima: PUCP.

CARMICHAEL, P., 1998 - Nasca ceramic production and social context. In: MASCA Research Papers in Science and Archaeology (I. Shimada, ed.): 213-231; Philadelphia.

CASTRO-POZO, H., 1924 - Nuestra Comunidad Indígena, 498 p.; Lima: El Lucero.

CEICAD, 1986 - Comercialización de ceramios en Simbilá, 85 p.; Piura: CEICAD, AAS.

CENSO, 1878 - Censo General de la República del Perú, formado en 1876, 9 vols.; Lima: Imp. del Teatro.

CERRÓN-PALOMINO, R., 1995 - La lengua de Naimlap, 220 p.; Lima: PUCP. 
CHIRINOS, R., LIRA, M. \& PUSCAN, R., 2005 - Los Huancas en Amazonas. Una aproximación a su cotidianidad y a la producción de su cerámica tradicional. Unay Runa, 7: 217-240.

CHRISTENSEN, R. T., 1955 [1950] - Una industria moderna de cerámica en Simbilá, cerca de Piura, Perú. Chimor. Boletín del Museo de Arqueología de la Universidad de Trujillo, 3: 25-32.

CLELAND, K. \& SHIMADA, I., 1994 - Ceramios paleteados: tecnología, esfera de producción y subcultura en el Perú antiguo. In: Tecnología y organización de la producción de cerámica prehispánica en los Andes (I. Shimada, ed.): 321-348; Lima: PUCP.

COLLIER, D., 1959 [1956] - Pottery stamping and molding on the North Coast of Perú. Actas del XXXIII Congreso Internacional de Americanistas, vol. II: 421-431; San José.

COOK, A. \& BENCO, N., 2000 - Vasijas para la fiesta y la fama: producción artesanal en un centro urbano huari. Boletín de Arqueología, 4: 489-504; Lima: PUCP.

CORREA, H., 1995 - Huarmaca. Ambito-Origen. Evolución-Perspectivas, 279 p.; Chiclayo.

DEPECHP, 1992 - Proyecto Chira-Piura. Anuario Meteorológico. Año 1973-1991; Piura: Senamhi, Dirección ejecutiva del Proyecto Especial Chira-Piura. División de Hidrometeorología.

DONNAN, C., 1965 - Moche Ceramic Technology. Nawpa Pacha, 3: 115-137.

DONNAN, C., 1971 - Ancient Peruvian potters marks and their interpretation through ethnographic analogy. American Antiquity, 36: 460-466.

DONNAN, C., 1997 - A Chimu-Inka Ceramic Manufacturing Center from the North Coast of Peru. Latin American Antiquity, 8: 30-54.

EECKHOUT, P., 2003 - Ancient monuments and patterns of power at Pachacamac (Central Coast of Peru). Beiträge zur Allgemeinen und Vergleichenden Archäeologie, 23: 139-182.

ESPEJO, J., 1951 - Los alfareros de Manka-Allpa. El Comercio, $1^{\text {ero }}$ de diciembre.

ESPINOZA, W., 1975 - El valle de Jayanca y el reino de los mochica siglos XV y XVI. Bulletin de l'Institut Français d'Études Andines, 4(3-4): 243-274.

ETESSE, G., 1991 - La sierra de Piura: ¿al margen de la evolución agraria andina? Bulletin de I'Institut Français d'Études Andines, 20(2): 599-620.

FONSECA, C., 1973 - Sistemas económicos andinos, 229 p.; Lima: UNMSM.

GOSSELAIN, O., 2002 - Poteries du Cameroun méridional, 254 p.; París : CNRS Éditions.

GROSSMAN, J., 1969-1970 - A Huaquero's Discard: Eleven Associated Molds from Huaca Facho, Peru. Nawpa Pacha, 7/8: 31-48.

GUFFROY, J., KAULICKE, P. \& MAKOWSKI, K. 1989 - La prehistoria del departamento de Piura: estado de los conocimientos y problemática. Bulletin de I'Institut Français d'Études Andines, 18(2): 117-142.

HAYASHIDA, F., 1995 - State Pottery production in the Inka provinces; Ann Arbor: Universidad de Michigan. Tesis de doctorado.

ISLA, J. 1992 - La ocupación nasca en Usaca. Gaceta Arqueológica Andina, 22: 119-151.

ISLA, J., REINDEL, M. \& DE LA TORRE, J. C., 2003 - Jauranga: un sitio Paracas en el valle de Palpa, costa sur del Perú. Beiträge zur Allgemeinen und Vergleichenden Archäeologie, 23: 227-274.

KELLEY, D., 1965 - Reseña a Lanning 1963. American Journal of Archaeology, 69: 291-293.

LANNING, E., 1963 - A ceramic sequence for the Piura and Chira coast, North Peru. Publications in American Archaeology and Ethnology, 46: 135-284; Berkeley/Los Angeles: University of California Press. 
LARCO, R., 2001 [1938-1939] - Los Mochicas, 2 vols.; Lima: Museo Rafael Larco Herrera, Grupo Telefónica.

LEERTOUWER, D., 1987 - Het traditionele Aardewerk aan de Noordkust van Peru, 118p.; Leiden: Rijksuniversiteit. Tesis de doctorado.

LITTO, G., 1976 - South American Folk Pottery, 223 p.; New York: Watson-Guptill Publications.

LYMAN, R. L. \& O'BRIEN, M., 2001 - The direct historical approach, analogical reasoning, and theory in americanist archaeology. Journal of Archaeological Method and Theory, 8: $303-342$.

MAKOWSKI, C., 1998 - Cultura material, etnicidad y la doctrina política del estado en los Andes prehispánicos: el caso mochica. Actas del IV Congreso Internacional de Etnohistoria, I: 125-147; Lima: PUCP.

MAKOWSKI, C., 2005 - La religión de las altas culturas de la Costa del Perú prehispánico. In: Religiones andinas (M. Marzal, ed.): 39-88; Madrid: Editorial Trotta.

MARTíNEZ COMPAÑON, B., 1985 [1790] - Trujillo del Peru, 13 vols.; Madrid: Cultura Hispánica.

MENZEL, D., 1976 - Pottery Style and Society in Ancient Peru. Art as a Mirror of History in the Ica Valley, 1350-1570, 275p.; Berkeley: University of California Press.

MOHR, K., 1984-1985 - Traditional pottery of Raqch'i (Cuzco, Perú): a preliminary study of its production, distribution and consumption. Nawpa Pacha, 22-23: 161-210.

MONZÓN, S., 1991 - El estudio de la cerámica y su contribución a una investigación interregional. El caso de Piura. Bulletin de l'Institut Français d'Études Andines, 20(2): 589-597.

MUÑINCO, A., 1991 - Ollas, anacos, sogas y brujos de Sondorillo. Informativo Regional de Piura, 177: 1-8; Piura: CIPCA.

ORME, B., 1981 - Anthropology for archaeologists, 300 p.; London: Duckworth.

POZZI-ESCOT, D., ALARCÓN, M. \& VIVANCO, C., 1993 - Instrumentos de alfarero de la época Wari (Ayacucho). Bulletin de I'Institut Français d'Études Andines, 22(2): 467-496.

PROULX, D., 1973 - Archaeological investigations in the Nepeña Valley (Peru), 293 p.; Amherst: University of Massachusetts, Department of Anthropology.

PURIN, S., 1983a - Utilisation des Rayons-X pour l'Observation des Traces de Fabrication sur Cinq Vases mochicas. Bulletin des Musées Royaux d' Art et d'Histoire, 2: 5-20.

PURIN, S., 1983b - La Fabrication des Vases mochicas de Type B, Utilisation des Rayons-X. Jaarboek 1983: 195-218; Mechelen: Vlaams Instituut voor Amerikaanse Kulturen.

QUIROZ, M., 1986 [1949-1950] - El Foto Óleo, 23 p.; Piura: CIPCA.

RADDATZ, C. (ed.), 1990 - Fotodokumente aus NordPeru von Hans Heinrich Brüning (1848-1928), 144 p.; Hamburg: Museum für Volkerkunde.

RAIMONDI, A., 1873 - El departamento de Ancachs y sus riquezas minerales, 651 p.; Lima: Imprenta de «El Nacional».

RAIMONDI, A., 1874 [1868] - El Perú, vol. 1; Lima: Imprenta del Estado.

RAIMONDI, A., 1901 [1868] - Itinerario de los viajes de Raimondi en el Perú (Piura). Boletín de la Sociedad Geográfica de Lima, 4-6: 121-163.

RAMÍREZ, M. J., 1966 - Huancabamba: su historia, su geografía y su folklore; Lima: Imprenta del Ministerio de Hacienda y Comercio.

RAMÓN, G., 1999-Producción alfarera en Santo Domingo de los Olleros (Huarochirí, Lima). Bulletin de l'Institut Français d'Études Andines, 28(1): 215-248. 
RAVINES, R., 1977 - Excavaciones en Ayapata (Huancavelica, Perú). Nawpa Pacha, 15: 49-110.

RESPALDIZA, J., 1953 [1945] - Un mito y un cuento de Simbilá. Folklore Americano, 1: 82-100.

REVESZ, B., ALDANA, S., HURTADO, L. \& REQUENA, J. (eds.), 1996 - Piura: Región y Sociedad. Derrotero bibliográfico para el desarrollo, 766 p.; Piura: CIPCA.

RICE, P., 1987 - Pottery analysis: a sourcebook, 559 p.; Chicago/London: The University of Chicago.

RICHARDSON, J., MC CONAUGHY, M., HEAPS, A. \& DÉCIMA, E., 1990 - The northern frontier of the kingdom of Chimor: the Piura, Chira and Tumbes valleys. In: The Northern dynasties: Kingship and statecraft in Chimor, (M. Moseley \& A. CordyCollins, eds.): 419-445; Washington: Dumbarton Oaks.

ROWE, J., 1955 - Time perspective in ethnography. Kroeber Anthropological Society Papers, 12: 55-61.

ROWE, J., 1959 - Archaeological Dating and Cultural Process. Southwestern Journal of Anthropology, 15: 317-324.

RUSSELL, G., BANKS, L. \& BRICEÑO, J., 1994a - Cerro Mayal: nuevos datos sobre la producción de cerámica moche en el valle de Chicama. In: Moche, propuestas y perspectivas (S. Uceda \& E. Mujica, eds.): 181-206; Lima: IFEA.

RUSSELL, G., BANKS, L. \& BRICEÑO, J., 1994b - Producción de cerámica moche a gran escala en el valle de Chicama, Perú: el taller de Cerro Mayal. In: Tecnología y organización de la producción de cerámica prehispánica en los Andes (I. Shimada, ed.): 201-227; Lima: PUCP.

RUSSELL, G. \& JACKSON, M., 2001 - Political Economy and Patronage at Cerro Mayal, Peru. In: Moche Art and Archaeology in Ancient Peru (J. Pillsbury, ed.): 159-175; New Haven/London: National Gallery of Art, Yale University Press.

RYE, O., 1981 - Pottery Technology. Principles and reconstruction, 150 p.; Washington: Taraxacum.

SABOGAL, J., 1978 - Siete sitios cerámicos en la región de Piura, 47 p.; Lima: Ministerios de Trabajo e Industria.

SABOGAL, J., 1981 - Alfarero de Huarmaca. Boletín de Lima, 3: 30-32.

SABOGAL, J., 1982 - La cerámica de Piura, 2 vols.; Quito: IAAP.

SABOGAL, J., 1987 - Cerámica yunga: estribación andino piurana, 52 p.; Piura: CIPCA.

SALAZAR, J., LÓPEZ, E. \& VREELAND, J. M., 1993 - Medida de las temperaturas de un horno artesanal de Mórrope (departamento de Lambayeque) utilizado para la fabricación de alfarería. Bulletin de I'Institut Français d'Études Andines, 22(3): 685-699

SALMON, M., 1982 - Philosophy and archaeology, 203 p.; New York/London: Academic Press.

SCHAEDEL, R., 1979 - The confluence of the pressed ware and paddle ware traditions in coastal Perú. In: Estudios Americanistas II. Homenaje a H. Trimborn: 231-239; Bonn: Instituto de Antropología.

SCHAEDEL, R., 1988 - La etnografía muchik en las fotografías de H. Brüning (1886-1925), 285 p.; Lima: Cofide.

SCHLÜPMANN, J., 1994 - La structure agraire et le développement d'une société régional au nord du Pérou (Piura, 1588-1854), 681 p. ; París : Université Paris VII-Denis Diderot.

SCOTT, S. M., 1895 - The huacos of Chira valley, Peru. American Anthropologist, 8: 8-22.

SHEPARD, A., 1965 - Ceramics for the archaeologist, 414 p.; Washington: Carnegie Institution. 
SHIMADA, I. ,1994a - La producción de cerámica en Mórrope, Perú. In: Tecnología y organización de la producción cerámica prehispánica en los Andes (I. Shimada, ed.): 295-320; Lima: PUCP.

SHIMADA, I., 1994b - Pampa Grande and the Moche Culture, 323 p; Austin: Texas University Press.

SILVERMAN, H., 1993 - Cahuachi and the ancient Nasca World, 371 p.; lowa: University of lowa Press.

SILVERMAN, H. \& PROULX, D., 2002 - The Nazca, 339 p.; Malden/London: Blackwell.

SPANHI, J.-C., 1966 - La cerámica popular del Perú, 131 p.; Lima: Peruano-Suiza.

SPANHI, J.-C., 1979 - Fabrication et décoration de la céramique populaire du Pérou. Bulletin de la Société Suisse des Américanistes, 43: 21-44.

SOSA, G., 1984 - El barro nos unió, 96 p.; Piura: CIPCA.

SPURLING, E., 1992 - The organization of craft production in the Inka state: the potters and weavers of Milliraya; Universidad de Cornell. Tesis de doctorado.

TELLO, J., 1938 - Arte Antiguo Peruano. Álbum fotográfico de las principales especies arqueológicas de cerámica Muchik existentes en los museos de Lima. Primera parte: tecnología y morfología. Inca, 2: VII-LXII, 1-280.

TILLMAN, H., 1978 - La alfarería piurana: símbolo de una cultura regional, 24 p.; Piura.

TORERO, A., 1986 - Deslindes lingüísticos en la costa norte peruana. Revista Andina, 8: 523-548.

TSCHAUNER, H., VETTERS, M., DULANTO, J., SACO, M. \& WESTER, C., 1994 - Un taller alfarero Chimú en el valle de Lambayeque. In: Tecnología y organización de la producción de cerámica prehispánica en los Andes (I. Shimada, ed.): 349-393; Lima: PUCP.

UCEDA, S. \& ARMAS, J., 1998 - An Urban Pottery Workshop at the Site of Moche, North Coast of Peru. In: MASCA Research Papers in Science and Archaeology (I. Shimada, ed.): 91-110; Philadelphia.

WILSON, D., 1988 - Prehispanic Settlement Patterns in the Lower Santa Valley Peru. A Regional Perspective on the Origins and Development of Complex North Coast Society, 590 p.; London/Washington: Smithsonian Institution Press.

WYLIE, A., 2002 - Thinking from things: essays in the philosophy of archaeology, 339 p.; Berkeley/Los Angeles: University of California Press.

YAMUNAQUÉ, J. 1979 - La cerámica: técnicas tradicionales. Historia y Cultura, 12: 151-164. 